\title{
Surgically Correctable Fetal Anomalies: Ultrasound Diagnosis and Management
}

\author{
Sanja Zaputovic, Milan Stanojevic, Ulrich Honemeyer, Tanja Turudic, Asim Kurjak
}

\begin{abstract}
A significant proportion of fetal anomalies are surgically correctable. Their accurate and reliable prenatal diagnosis is of great importance, and will have significant influence on both postnatal and postsurgical outcome. The influence of prenatal diagnosis of simple structural defects will interfere with organ development. In the light of recent achievements, traditional teratology has to be reexamined more critically.
\end{abstract}

Keywords: Fetal anomalies, Prenatal diagnosis, Ultrasound, Surgical correction.

How to cite this article: Zaputovic S, Stanojevic $M$, Honemeyer U, Turudic T, Kurjak A. Surgically Correctable Fetal Anomalies: Ultrasound Diagnosis and Management. Donald School J Ultrasound Obstet G ynecol 2012;6(3):237-256.

\section{Source of support $\mathrm{Nil}$}

Conflict of interest: None declared

\section{INTRODUCTION}

Fetal congenital malformations, whose cause is unknown in almost $70 \%$ of cases, continue to represent a significant and growing problem of perinatal morbidity and mortal ity. ${ }^{1}$ The proportion of postnatal morbidity attributable to congenital malformations has also increased. U nfortunately, prevention of congenital malformations is mostly unavailable, and the only real istic approach is early antenatal diagnosis of gross congenital malformations and termination of pregnancy when dealing with malformations incompatiblewith life. However, during the recent 5 decades, advances in diagnostic and surgical techniques have provided a new opportunity for prenatal prevention of certain congenital malformations and fetal therapy in some rare conditions, enabling the fetus to become a patient. For more than 30 years it is possible to identify fetal conditions and sometimes to treat the fetus actively and successfully even when dealing with severe congenital malformations. ${ }^{2-5}$

$M$ any fetal abnormalities can now be detected. Most defects are best treated after birth, and prenatal diagnosis improves outcome enabling optimal postnatal care. Only a few disorders are potentially amenable to treatment before birth. ${ }^{2-5} \mathrm{~N}$ ew, very sophisticated, surgical techniques enable the possibility for such correction. The malformations that warrant consideration for treatment in utero are simple structural defects that interfere with organ development and whose alleviation might allow fetal development to proceed normally. At present, congenital diaphragmatic hernia, hydronephrosis and hydrocephalus are the candidates. In the light of these achievements, traditional teratology has to be reexamined meaning that simple description or morphology of malformations is no longer sufficient. The pathogenesis of malformations has to be evaluated with reference to the organogenesis for better planning secondary and tertiary prevention of the congenital malformations. A lthough, the emphasis of treatment of congenital anomalies has been on surgery, we believe that it is important to diagnose these abnormalities al ready in utero. Since, there is no existing specialty which has all the knowledge and technical expertize to handle the potential myriad of intrauterine pathology, it is important that these fetuses are evaluated and treated in a medical setting with a team providing knowledge and expertize in areas of genetics, neurosurgery, gastroenterology, urology, neonatology, pediatric surgery and perinatology. ${ }^{6}$ Postnatal diagnosis of these conditions comes largely from recognition of certain clinical findings in the neonatal period often followed by imaging techniques to make correct and timely diagnosis.

The aim of the paper is to present the data on surgically correctable congenital malformations in the 6 years period in the tertiary medical institution of perinatal care, their management and outcome.

\section{MATERIALS AND METHODS}

In the 6 years period (from 2005 to 2010), there were 19,876 live-born neonates of whom 198 (1\%) have been prenatally diagnosed with surgically correctable congenital malformation. The case records of these children and of other children with the same condition diagnosed postnatally- have been studied in order to assess the accuracy of the prenatal diagnosis and its potential influence on the neonatal management and outcome. The prevalence rate of congenital malformations in the 6 years period is presented in the Figure 1.

Total number of live-borns was 19,876, 198 (prevalence rate $1 \%$ ) with surgically correctable gross congenital malformations.

\section{RESULTS}

\section{Urinary Tract}

There were 58 out of 198 infants with urinary tract congenital malformations detected prenatally which was 


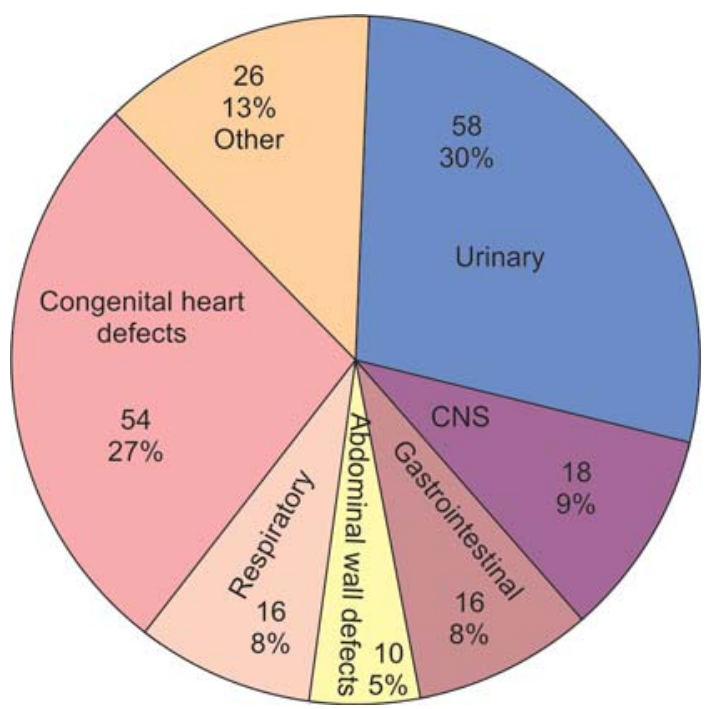

Fig. 1: Prevalence of surgically correctable anomalies in the 6 years period

$30 \%$ of all mal formed fetuses or $0.3 \%$ of live-born neonates (Fig. 1). Successful and accurate antenatal diagnosis of urinary tract malformations could influence their management. Some cannot be corrected and most of the correctable lesions are best treated after normal term delivery. How ever, a few are amenable to treatment before term. Prenatal ultrasonography may be helpful for making postnatal treatment more efficient and clinicians and parents more aware of the nature of the malformation. ${ }^{7}$ From the practical point of view fundamental distinction should be made between unilateral and bilateral malformations of urinary tract. If one is dealing with unilateral conditions like multicystic kidney or unilateral hydronephrosis meaning that the other kidney is healthy, then prenatal intervention is mostly not indicated. Only weekly ultrasonographic check ups till delivery will be sufficient. At birth, the newborn will undergo all necessary check ups including clinical examination, laboratory work-up and imaging. ${ }^{8,9}$ As soon as a certain diagnosis is available, surgical correction will be performed at the most appropriate time. If there is massive enlargement of the fetal abdomen, elective cesarean delivery should be considered to prevent the dystocia that might occur with vaginal delivery and to prevent further damage to these vital organs.

In bilateral renal agenesis, bilateral multicystic kidneys, or bilateral infantile polycystic kidneys are demonstrated early in gestation, the obstetrician and parents may choose to terminate the pregnancy because these conditions are not compatible with extrauterine life. ${ }^{10}$

Ultrasound examination in pregnancies at increased risk with family history of B ardet-B iedl syndrome (BBS) should seek prenatal diagnosis using second-trimester ultrasound examination to detect anomalies, such as postaxial polydactyly and renal cysts, found in BBS as reported by Dar et al 2001. ${ }^{11,12}$ BBS is an autosomal recessive disorder characterized by postaxial hexadactyly, obesity, mental retardation, pigmented retinopathy, hypogonadism and renal disease. $^{13}$

M orphological changes are present in all areas of the kidney, the renal medulla being the most frequently affected site. Cystic and dysplastic changes are prevalent. Cassart et al studied 11 pregnancies by ultrasound examination and concluded that in families in which BBS had occurred previously, the prenatal appearance of enlarged hyperechoic kidneys without corticomedullary differentiation should be considered recurrence of BBS. ${ }^{14}$

\section{Obstructive Uropathies}

Prenatal diagnosis of obstructive uropathies (Figs 2A to D) opens new possibilities in the pediatric urologic management of these lesions, and the benefits of fetal ultrasonography are now increasingly evident. This is particularly significant since, data suggest that relief of obstruction in the young infant (under the age of 12-18 months) is associated with improvement in renal function, while in the older child, renal function stabilizes only after surgical repair. M ale infants with posterior urethral valves often demonstrate renal failure, dehydration and sepsis at the age of 2 to 4 weeks.

If this diagnosis is anticipated at birth, initial transurethral catheterization and subsequent endoscopic destruction of the valves would minimize the risk of further damage from prolonged obstruction and infection. Likewise, the infant with bilateral ureteropelvic or ureterovesical obstruction, or obstruction of a solitary renoureteral unit could be operated on early and electively. ${ }^{9,14}$ Several problems remain, however, which must be resolved to obtain maximum benefit from early detection in utero. Since, not all obstructions are severe, despite marked dilatation of collecting system, the criteria like renal parenchymal growth, changes in renal pelvic size, fetal urine flow should be taken into account to establish the follow-up of renal damage, which, if progressive would justify early delivery for urgent surgical management of obstructive uropathy. While definitive surgical repair may be difficult or impossible in a tiny, premature infant, temporary cutaneous diversions (pyelostomy, ureterostomy, vesicostomy) could be accomplished at any age or size, if necessary. ${ }^{9}$

Fetal diagnosis of congenital paraureteral urinary bladder or so called Hutch diverticula associated with vesicoureteral reflux (VUR) influences postnatal management significantly. VUR is the most common urologic diagnosis in children, occurring in approximately $1 \%$ of newborns 

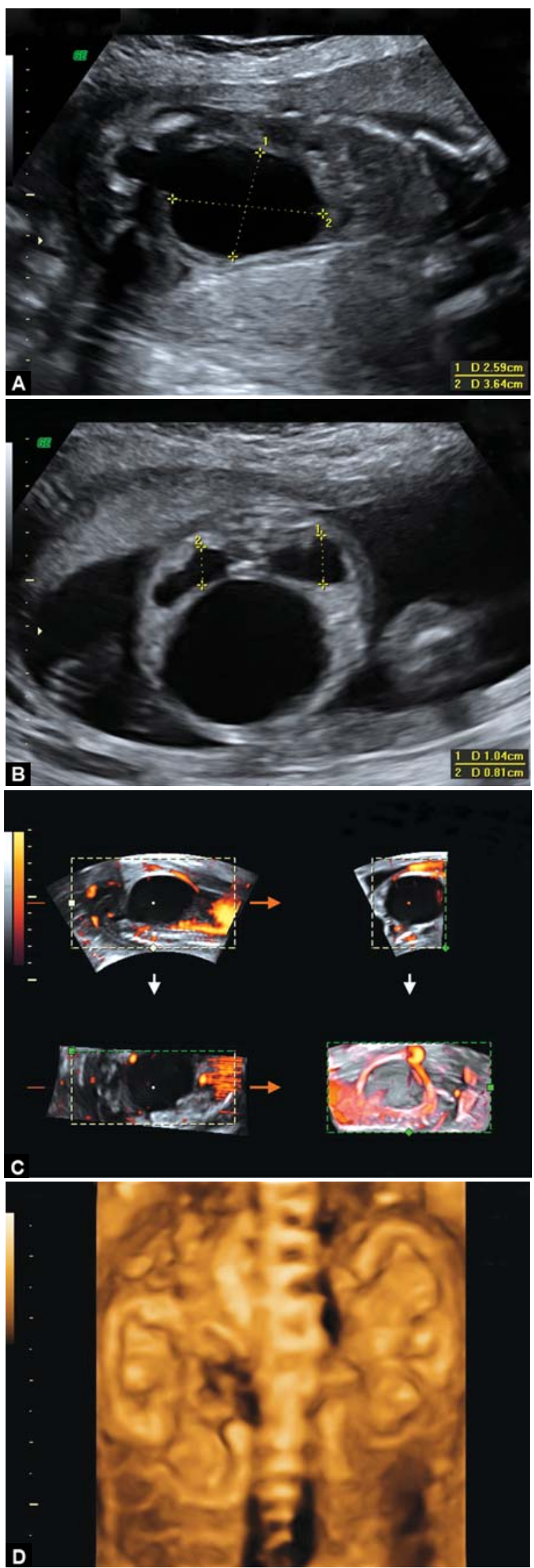

Figs 2A to D: Obstructive uropathy: (A) Enlarged urinary bladder, (B) megacyst and bilateral hydronephrosis transverse view, (C) multiplanar power Doppler view with encircling umbilical arteries around the enlarged bladder, (D) 3D surface rendered view of bilateral hydronephrosis and as high as 30 to $45 \%$ in children with urinary tract infection (UTI). Current management is based upon the long-held belief that VUR is a risk factor for renal scarring because it predisposes patients to recurrent acute pyelonephritis by transporting bacteria from the bladder to the kidney. The development of renal scarring increases the risk of hypertension and chronic kidney disease (CKD). ${ }^{15}$

Where obstructive lesion are evidently leading to progressive renal damage at a time when premature delivery cannot be reasonably undertaken, early intervention is necessary, because if unrelieved, the obstruction interferes with the fetal development and the severity of damage depends on the degree and duration of obstruction.

Prune belly syndrome (PBS) incidence is estimated to be 1 in 30,000 to 50,000 newborn babies. A t an early stage during the first trimester screening, key hole sign of dilated proximal urethra, and oligohydramnios are not yet visible.

There are several alternatives for decompressing an obstructed fetal urinary tract. The fetal bladder or renal pelvis can be aspirated percutaneously under ultrasonographic guidance. A nother possibility is early delivery and decompression of the urinary tract ex utero, This will maximize the opportunity for further renal development and minimize the adverse effects of oligohydramnios. The ideal management is early decompression of the urinary tract and continued gestation. The first successful urinary tract bypass in utero was performed by Golbus and others in 1982 who developed techniques for the ultrasonographically guided percutaneous placement of fetal shunt catheters and for the surgical exteriorization of the fetal urinary tract. ${ }^{16}$

When the performance of urinary tract diversion is being considered, we are very much of the opinion that the risks of shunt placement are too high in the case of unilateral lesion or those causing mild bilateral hydronephrosis associated with normal amniotic fluid index. If serial scans show progressive bilateral renal calicle dilatation, in association with increasing oligohydramnios in a fetus too premature for delivery, surgical intervention may be plausible. However, at present we do not know whether such intervention would be justified in terms of the optimal additional time to be gained in utero. Once a shunting procedure is to be attempted when obstruction seems complete in the second trimester, the parents should be warned that irreversible changes may al ready have occurred and that operation which could appear to be technically successful, may nevertheless be of no benefit. ${ }^{17}$

If upon initial scanning, a patient with pulmonary immature fetus, in the third trimester, appears to have a bilaterally obstructed fetal genitourinary system with accompanying oligohydramnios, a shunt would probably be advisable. Decompression of the obstructed system in a 
situation where the kidneys are not dysplastic may prevent further renal damage, and correction of the oligohydramnios could save the life of the fetus. Irreversible renal or pulmonary damage may al ready have occurred, but it cannot be determined prior to delivery. In cases of significant oligohydramnios, the insertion of a bladder- amniotic fluid shunt is a considerable technical problem as the placement of the distal end of the catheter within the amniotic sac is hindered by low volume of amniotic fluid. As further experience in the treatment of genitourinary lesion in utero reported, it will be possible to develop guidelines for the selection of appropriate patients. In the meantime, the management of these cases should be undertaken by a team of experts including the obstetrician, neonatologist and pediatric urologist, meeting regularly to discuss progress after each ultrasonic examination. ${ }^{18}$ The neonatal surgeon will also observe number of cases simply suspected or diagnosed in utero as being at the 'limit of indication for intervention,' showing a light obstructive uni-or bilateral pathology.

Future serial tests and experience over the next years will indicate how such cases should be managed: Whether to operate in the 1st weeks, or after 6 or 12 months, or not operate at all.

Thus, fetal hydronephrosis is the consequence of the obstruction at the level of the urethra, the vesicoureteric orifice, the pelviureteric junction or associated with vesicouretheric reflux. It is the most common urinary tract abnormality. The ureteropelvic junction is the most common site of congenital urinary obstruction above the level of the bladder. ${ }^{19,20}$ The resulting hydronephrosis may be unilateral or bilateral.

In adults, pulsed Doppler sonography was used for the diagnosis of lower pole arteries, which cross the ureteropelvic junction and are possibly the reason for hydronephrosis. ${ }^{21}$ Prenatal diagnosis has become possible through combined use of three-dimensional (3D) sonography and power Doppler allowing topographic evaluation of renal arterial blood flow and surface rendered renal pelvis anatomy.

To evaluate efficacy of laparoscopic management of ureteropelvic junction obstruction, 329 patients underwent laparoscopic transperitoneal ureteropelvic junction obstruction management from June 2001 to $M$ arch 2009. Intraoperatively, lower pole crossing vessels were identified in 117 patients (35.5\%). Laparoscopic cephalad relocation of the lower pole crossing artery after division of the crossing vein in selected cases was found to be an ideal al ternative for dismembered pyeloplasty with noticeable outcomes in long-term follow-up. ${ }^{22}$

\section{Multicystic Kidney}

Multicystic kidney is the most common of all neonatal abdominal masses and this condition represent $20 \%$ of all masses. As it is no threat to life in the immediate neonatal period, accurate diagnosis by noninvasive means distinguishes it from other neonatal abdominal masses. The diagnosis of a multicystic kidney is suggested by the presence of multiple cysts. The cysts are commonly of the order 1 to $2 \mathrm{~mm}$ in diameter but they can be up to $6 \mathrm{~mm}$ large. A similar cystic appearance may sometimes be produced by hydronephrosis, but multicystic kidney disease is nearly always bilateral; Dilatation of the ureters and kidneys may be either unilateral or bilateral depending on the site of the obstruction. ${ }^{23}$

\section{Congenital Renal Tumors}

Congenital renal tumors are rare with 2.5 to $7 \%$ of all perinatal tumors. In decreasing order of frequency they could appear as congenital mesoblastic nephroma, W ilms tumor, rhabdoid tumor, clear cell sarcoma, hamartomas (e.g. angiomyolipoma), and ossifying tumor of infancy. Congenital mesoblastic nephroma (CMN) is generally benign. It develops from renal mesenchyma. Less than $5 \%$ of all pediatric renal tumors turn out as CM N. A round $90 \%$ are diagnosed during the first year of life, 50 to $75 \%$ are found in infants before they reach 3 years of age. ${ }^{24}$ Prenatal diagnosis of mesoblastic nephroma (Bolande's tumor) by ultrasound is increasing. Findings of a 'ring' sign, an anechoic ring surrounding the tumor, were described as typical for mesoblastic nephroma. D oppler signals registered in the ring indicated intense peripheral vascularity, and histopathological evaluation confirmed the vascular origin of the ring sign..$^{25}$ The most common presentation is as a unilateral solid mass with homogeneous echogenicity near the renal hilus. There is no discernable capsule, but the mass is well-demarcated from the renal tissue. Because polyhydramnios is seen in about $70 \%$ of all cases, $25 \%$ of cases devel op uterine contractions and deliver preterm. The prognosis is excellent after unilateral nephrectomy. ${ }^{26}$

\section{Central Nervous System}

\section{Hydrocephalus}

Hydrocephalus (Figs $3 A$ and $B$ appearance of the infant head; Fig. 4 postnatal 3D ultrasound) does not indicate a single clinical entity, but includes a variety of clinicopathological conditions caused by excessive cerebrospinal fluid (CSF) based on the disturbed circulation. ${ }^{27} \mathrm{~N}$ ew standards for clinicopathological evaluation of hydrocephalus as well as the classification of 


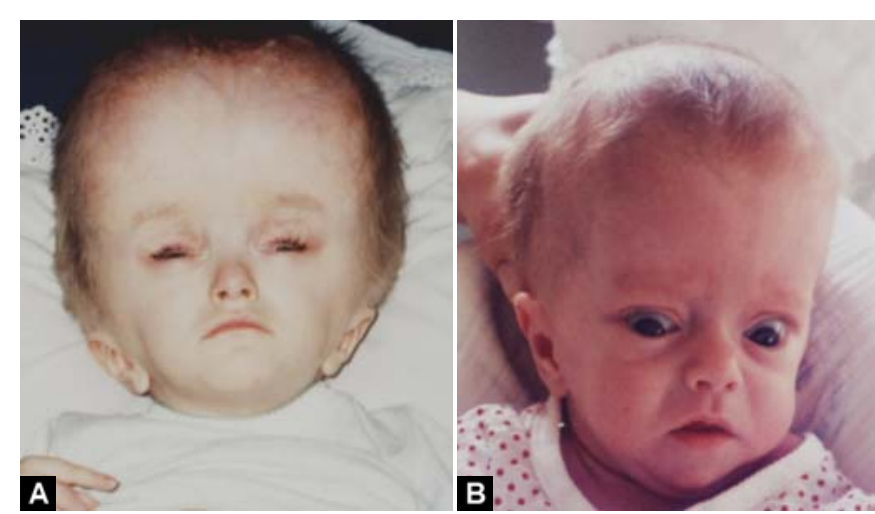

Figs $\mathbf{3 A}$ and B: (A) Excessive hydrocephaly, (B) setting-sun sign

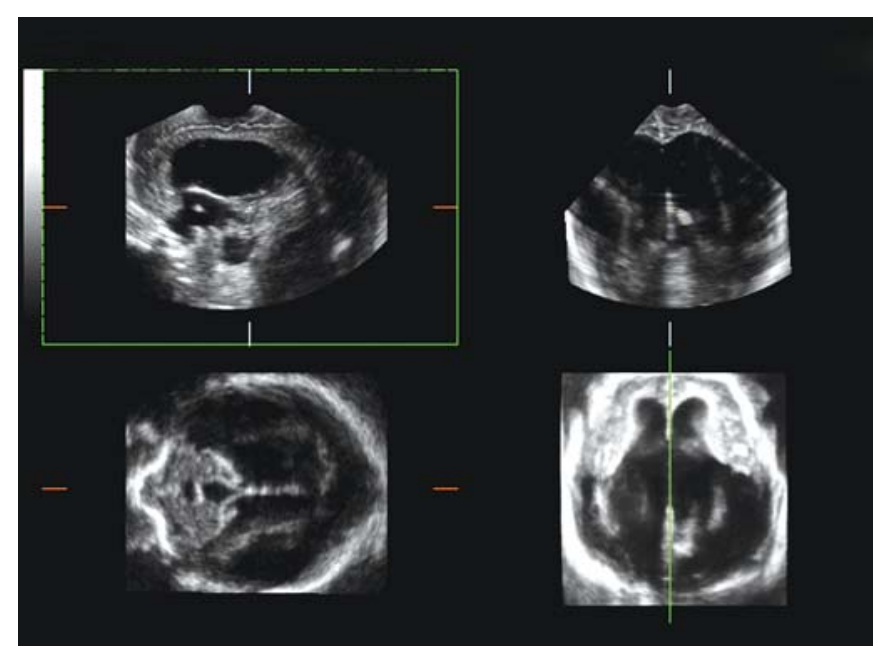

Fig. 4: P ostnatal 3D ultrasound: Multiplanar view of prenatally developed posthemorrhagic hypertensive hydrocephalus

hydrocephalus have been developed in J apan. ${ }^{27}$ The most important clinical conditions associated with hydrocephalus are: Aqueductal stenosis, myelomeningocele, postintraventricular hemorrhage due to prematurity, congenital hydrocephalus, cyst, tumor, post-head-injury, postinfectious and other. ${ }^{28}$ Hydrocephalus with high intracranial pressure is one of the causes of severe brain damage in fetuses and in newborns if not treated. The prevalence rate in Europe is 5.84 per 10,000 births after 20 weeks of gestation. ${ }^{29}$ It is essential to make assessment of the intracranial pressure and condition of the brain and perform the derivation of CSF at the earliest opportunity in order to avoid brain damage. ${ }^{27,30,31}$ The ultimate goal of hydrocephalus treatment remains achieving arrested hydrocephalus by shunt surgeries. In the future, to achieve arrested hydrocephalus, minimum quantity of CSF to be drained should be elucidated. ${ }^{27} \mathrm{High}$ intracranial pressure can cause marked separation of cranial sutures and the setting-sun sign (Figs $3 A$ and $B$ ).

Clinical neurological and ophthalmological assessment together with head ultrasound have been performed in all babies postnatally, while magnetic resonance imaging
(M RI) or multislice-computed tomography (M SCT) were done when needed. Based on all the findings, neurosurgical treatment has been indicated whenever appropriate. A favorable outcome was reported for $66.8 \%$ of patients, $31.5 \%$ showed no change, while overall inpatient mortality was $1.7 \% .{ }^{32}$ Concerning the long-term outcome in one study 132 patients underwent 179 shunt surgeries. Forty-four (33\%), $79(60 \%)$ and 99 (75\%) patients demonstrated objective improvement at 3, 6 and 24 months after shunt surgery respectively. Gait improved first in 88 (93\%) patients. ${ }^{32}$ Dementia and urinary incontinence were twofold less likely to improve. Radiological evidence of corpus callosum distension, gait impairment as the primary symptom predicted improvement. ${ }^{33}$

Posthemorrhagic hydrocephalus and hydrocephalus connected with craniospinal dysraphism had significantly earlier revisions than congenital and other etiologies. ${ }^{34}$

\section{Neural Tube Defects}

A ccording to EUROCAT prevalence rate of all neural tube defectes in Europe from 2005 to 2009 was 9,74 per 10,000 births. ${ }^{29}$ Prevalence rate of specific malformations per 10,000 births after 20 weeks of gestation were: Encephalocele, 1.17; spina bifida, $4.98 .^{29}$

\section{Encephalocele}

Encephalocele is a neural tube defect characterized by protrusion of the brain and meninges through opening in the cranium. The most common localization is occipital region (67\%) of the skull (prenatal US diagnosis depicted at Figs $5 \mathrm{~A}$ to $\mathrm{C}$ ), often associated with hydrocephalus $(45.8 \%)$. Surgery should be performed as early as possible and only after careful preoperative planning especially for the anterior encephalocele. ${ }^{35,36}$

\section{Spina Bifida and Meningomyelocele}

Spina bifida, often prenatally detected during the second and the third trimester, is one of the CNS anomalies with the indication for immediate surgical correction after birth (Figs 6 to 7D). Spina bifida malformations fall into three categories: Spina bifida occulta, spina bifida cystica with meningocele and spina bifida cystica with myelomeningocele. ${ }^{37}$ The most common location of the malformations is the lumbar and sacral areas (Fig. 7A). M eningomyelocele is the most significant form causing disability in most affected individuals. The incidence of spina bifida can be decreased by up to $70 \%$ when daily folic acid supplements are taken prior to conception. ${ }^{38}$ Significant ethnic differences in prevalence are recognized; people of Celtic 

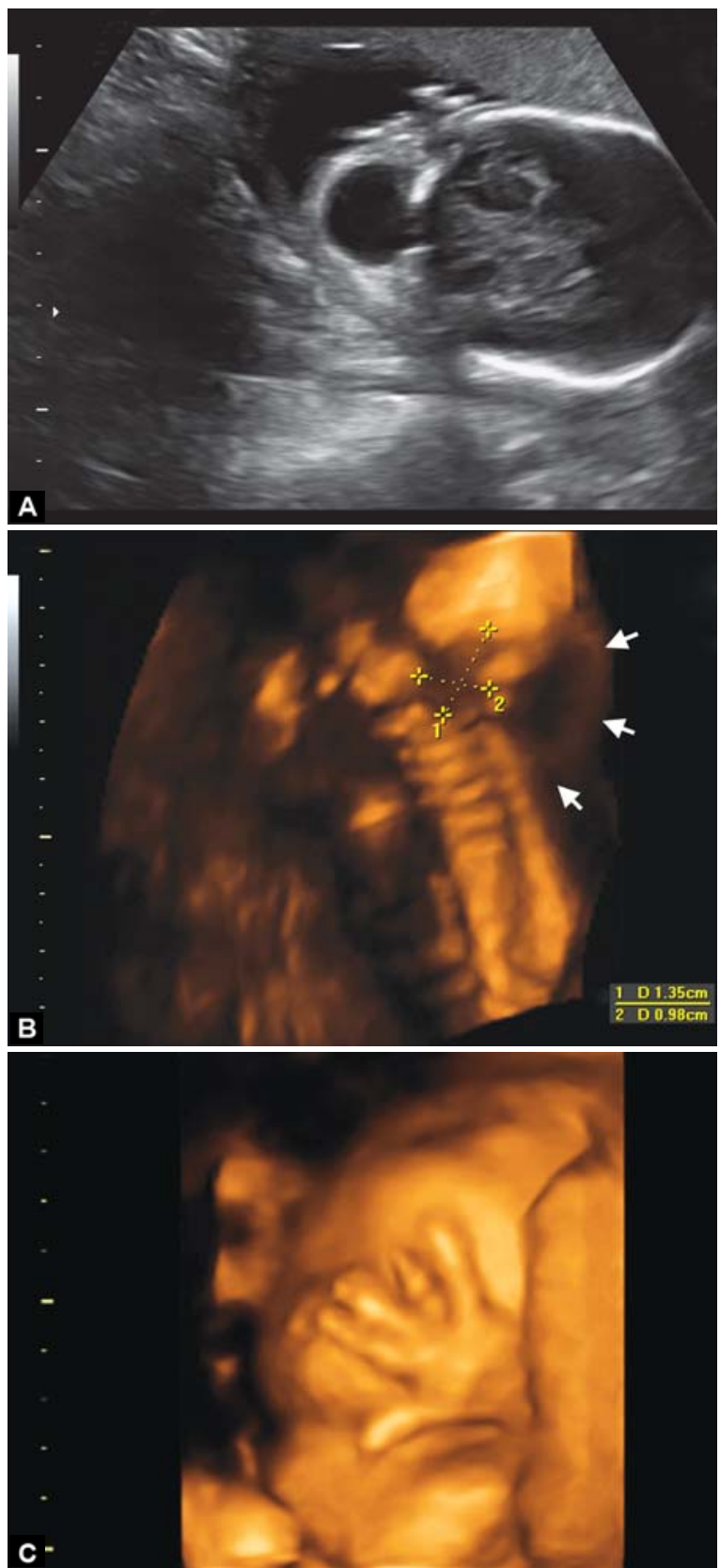

Figs 5A to C: Occipital encephalocele: (A) B-mode, (B) surfacerendered $3 \mathrm{D},(\mathrm{C})$ capture of $4 \mathrm{D}$ sequence with variable fingermovements

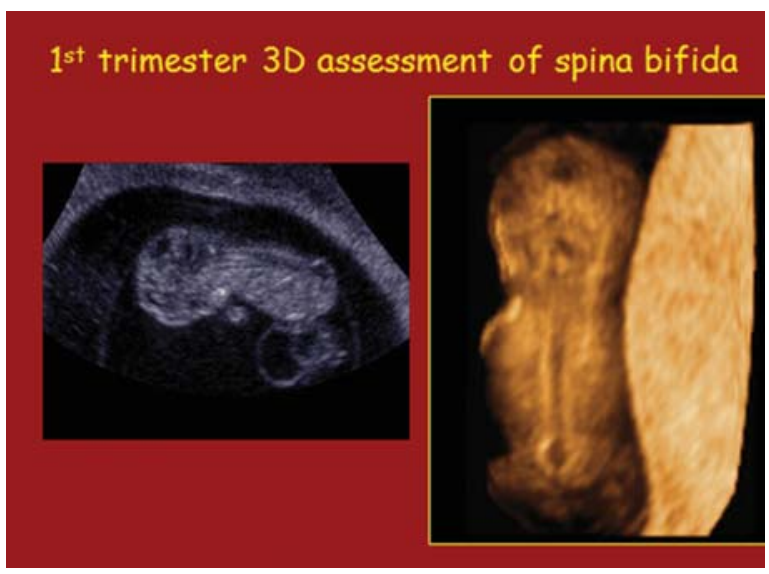

Fig. 6: Spina bifida diagnosed in the first-trimester (Courtesy: DrR Pooh)

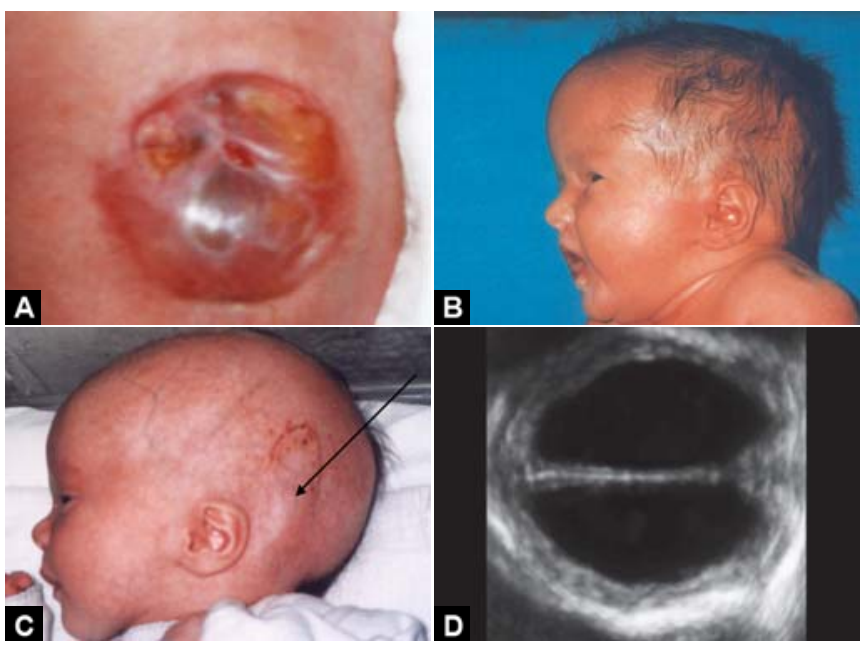

Figs 7A to D: Postnatal photo of lumbosacral meningomyelocele: (A) With consecutive hydrocephally (type II Arnold-Chiari malformation) (B), (C) shunt operation (outer part of the shunt placed behind the left ear-arrow), (D) ultrasound image of enlarged brain ventricles

origin have the highest rate of spina bifida. A female predominance is observed, with females accounting for 60 to $70 \%$ of affected children.

\section{Vein of Galen Aneurysm Malformation}

The vein of $\mathrm{G}$ alen aneurysm is a rare vascular malformation consisting of one or more arteriovenous shunts from arterial feeders from the carotid and vertebrobasilar systems in the midbrain, to the vein of $\mathrm{G}$ alen. ${ }^{39}$ The malformation is due to an arteriovenous fistula of the median prosencephalic vein, a precursor of the vein of $\mathrm{G}$ alen, which fails to regress. High flow of blood into the vein causes it to dilate, it is however, not a true aneurysm. ${ }^{39}$ The high rate of blood flow may result in cardiac failure due to increasingly pronounced venous return via jugular veins and vena cava superior. As much as $80 \%$ of the cardiac output may shunt through the fistula. The sonographic appearance of the dilated vein of Galen in the mid-sagittal plane is a large, well-defined, irregular, supratentorial, and sometimes pulsatile structure, along the corpus callosum above the cerebellum to the calvaria. ${ }^{39}$ In the coronal plane, the dilated vein appears as a round, cystic, centrally located structure. ${ }^{39}$ In color Doppler imaging, the focal lesion fills with blue-orange (aliasing) color signals due to turbulences of venous flow (Figs $8 \mathrm{~A}$ to D). ${ }^{39}$ Other sonographic findings include dilated jugular veins and vena cava superior, signs of high output heart failure, such as cardiac dilatation, fetal hydrops, and polyhydramnios. The enlarged vein of Galen may cause obstruction of the ventricular system through compression of the Sylvian aqueduct, eventually with resulting hydrocephaly. Neonatal vein of Galen aneurysm 

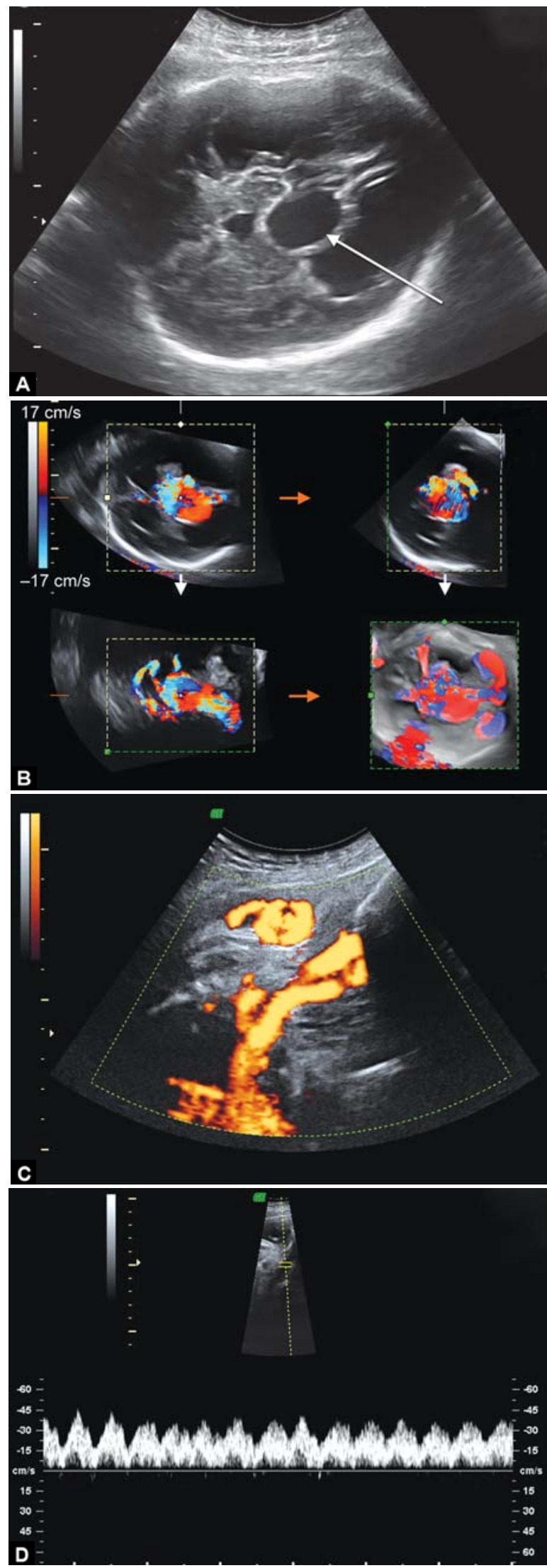

Figs 8A to D: VGAM (prenatal diagnosis): (A) 2D image (B) color Doppler, (C) power Doppler, (D) pulsed Doppler wave

malformation (V GAM ) can be treated successfully with a strategic approach integrating antenatal diagnosis,
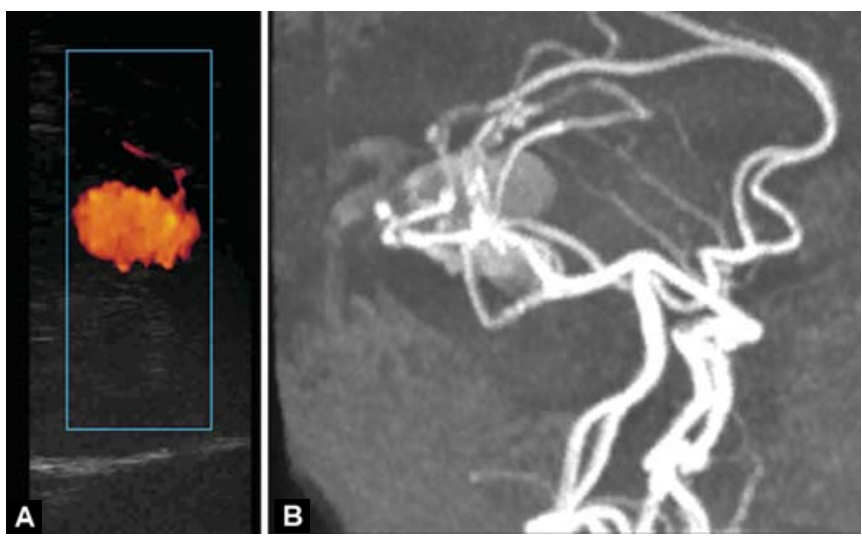

Figs 9A and B: Postnatal images of vein of Galen aneurysm: (A) postnatal power Doppler and (B) magnetic resonance angiography

endovascular surgery, treatment at intensive care facilities, and the cooperative efforts of different specialties. B oth venous and arterial embolization is possible, either with coils or acrylic glue. Patients in whom VGAM was diagnosed (postnatal diagnosis of VGAM; Figs $9 A$ and $B$ ) and managed in infancy or childhood had more than $90 \%$ longterm survival. The better prognosis is largely determined by absence of cardiac failure. ${ }^{40,41}$

\section{Fetal Intracranial Hemorrhage}

Hemorrhages may occur either within the cerebral ventricles, subdural space or infratentorial fossa. It has been estimated that the incidence of intracranial hemorrhage $(\mathrm{ICH})$ in premature infants is high, occurring in approximately $40 \%$ of infants of less than 32 weeks gestation. A ntenatal fetal $\mathrm{ICH}$ may occur spontaneously, or occur in association with various maternal or fetal conditions (Figs $10 \mathrm{~A}$ to $\mathrm{H}$ ). Predisposing maternal conditions at risk for this occurrence include alloimmune and idiopathic thrombocytopenia, von Willebrand's disease, specific medications (warfarin) or illicit drug (cocaine) abuse, seizures, severe abdominal trauma inflicting subsequent fetal injury, amniocentesis, cholestasis of pregnancy and febrile disease. Predisposing fetal conditions include congenital factor- $X$ and factor- $V$ deficiencies, hemorrhage into various congenital tumors, twin-twin transfusion, demise of a cotwin or fetomaternal hemorrhage. ${ }^{42-45}$ The classification of ICH includes five major types: Intraventricular hemorrhage (IVH), cerebellar, subdural, primary subarachnoid hemorrhages and miscellaneous intraparenchymal hemorrhages. ${ }^{45} \mathrm{IV} \mathrm{H}$ s are the most common variety of neonatal ICH and are characteristic of the immature brain. IV Hs are subdivided according to their severity into four grades; The first three grades are limited to the ventricles, while the fourth grade includes parenchymal involvement occurring in the most severe cases. ${ }^{45}$ 


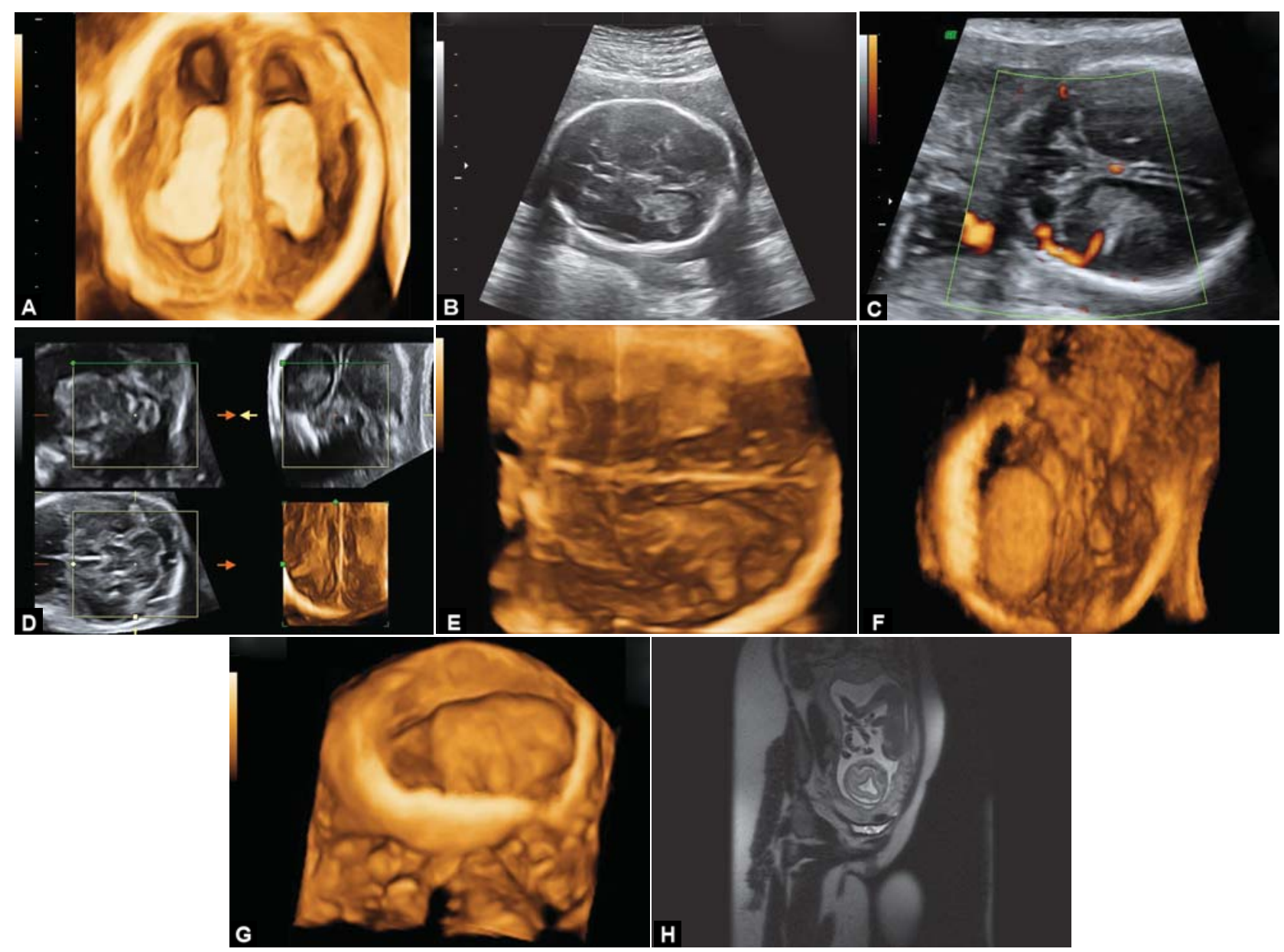

Figs 10A to H: (A) Normal 3D image of the fetal head-lateral ventricles and choroid plexus at 16 weeks, (B) 2D-IVH at 22 weeks and 1 day of gestation, (C) power Doppler of IVH, (D) 3D multiplanar view and 3D reconstruction of the IVH, (E) 3D reconstruction of the IVH in the posterior horn of left lateral ventricle, (F) 3D reconstruction of the IVH in the posterior horn of left lateral ventricle-ventriculomegaly at 23 weeks and 4 days, (G) 3D reconstruction of the IVH in the posterior horn of left lateral ventricle-ventriculomegaly, (H) MR of IVH in the posterior horn of left lateral ventricle

Transabdominal or transvaginal ultrasound can present with different sonographic features, such as hyperechoic lesions in the lateral ventricle and ventriculomegaly, irregular echogenic brain mass, intraventricular echogenic foci or periventricular echodensities and posthemorrhagic hydrocephalus (PHH) (Fig. 4). The outcome is usually poor, especially for those fetuses affected by higher grade IV H. V entriculoperitoneal shunting postpartum in case of $\mathrm{PHH}$ constitutes an option to enable best as possible neurological development. 43,45

Due to the significant associated neonatal neurological impairment and potential medicolegal implications of antepartum fetal intracranial hemorrhage, it follows that obstetricians and sonographers should be familiar with predisposing factors and typical diagnostic imaging findings of these events. In addition to this, intrauterine fetal behavior visualized with 4D ultrasound can be successfully evaluated with the new Kurjak antenatal neurodevelopmental test (KANET), providing possibilities of prenatal diagnosis of fetal neurological impairment. ${ }^{46}$

\section{Fetal Face}

\section{Cleft Lip and Palate}

Prevalence of orofacial clefts is 15.96 per 10,000 births (cleft lip with or without cleft palate 9.41 and cleft palate 5.45 per 10,000$).{ }^{29}$ Cleft lip occurs unilaterally or bilaterally, and in less than $10 \%$ of babies it can be associated with abnormal karyotype. Recent 3D tomographic ultrasound can demonstrate the anterior maxillary structure, showing evidence of alveolar cleft (Figs 11A to C). Prenatal diagnosis is helpful in psychological preparation of parents for the cosmetic implications of the neonate (postnatal appearance- Figs $12 \mathrm{~A}$ to $\mathrm{C}$ ), and in organizing immediate postnatal provision of a palatal plate to enable sucking and better growth of malformed maxilla enabling more successful surgical repair in the future. ${ }^{47}$ Functional and cosmetic repair of even deep clefts involving the orbita is usually completed before 10 years of age. ${ }^{48}$

A ntenatal sonographic diagnose of skin tags (prenatal diagnosis-Figs $13 \mathrm{~A}$ and $\mathrm{B}$ ) of the fetal face may possess 

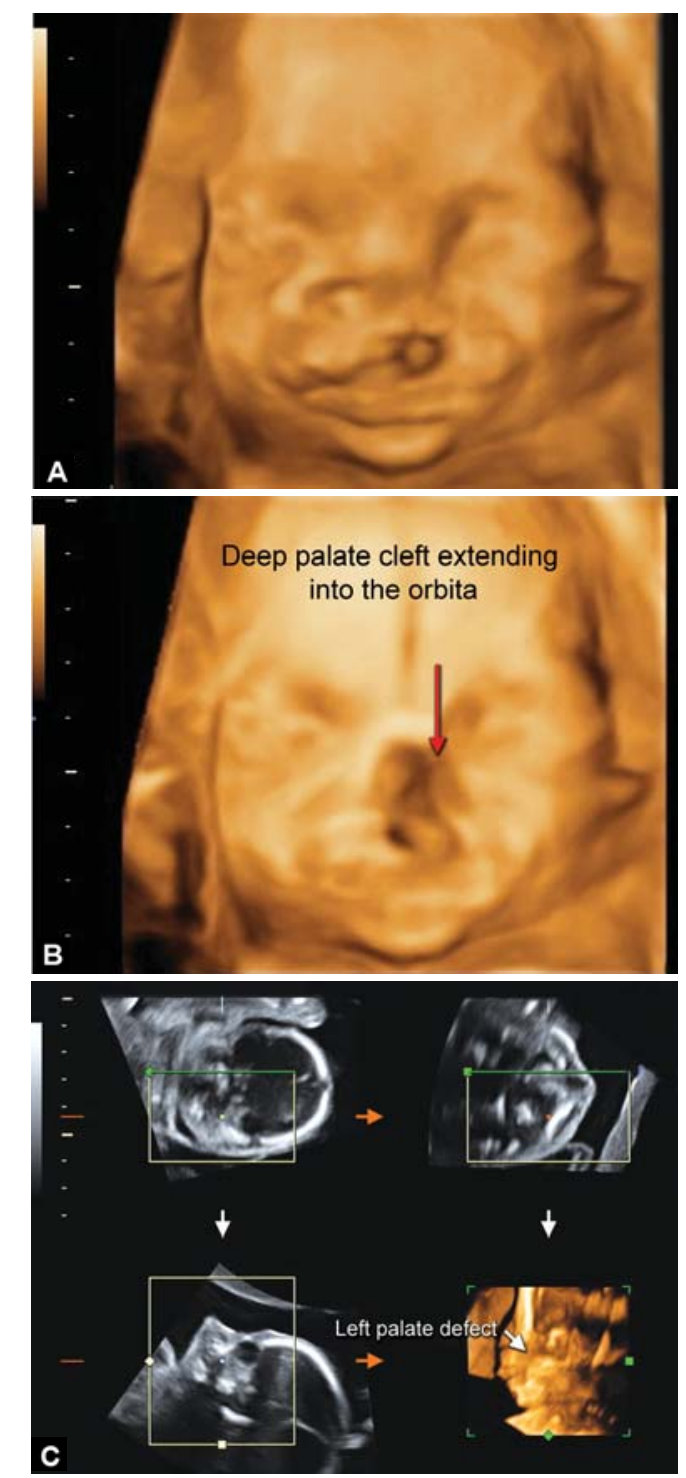

Figs 11A to C: Cleft lip and palate: (A) 3D surface rendering of cleft lip, (B) cleft palate 3D surface rendering, (C) 3D multiplanar view

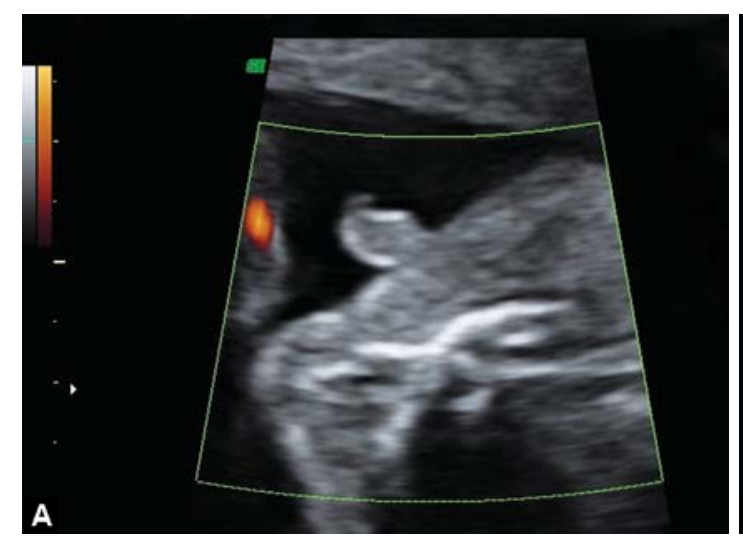

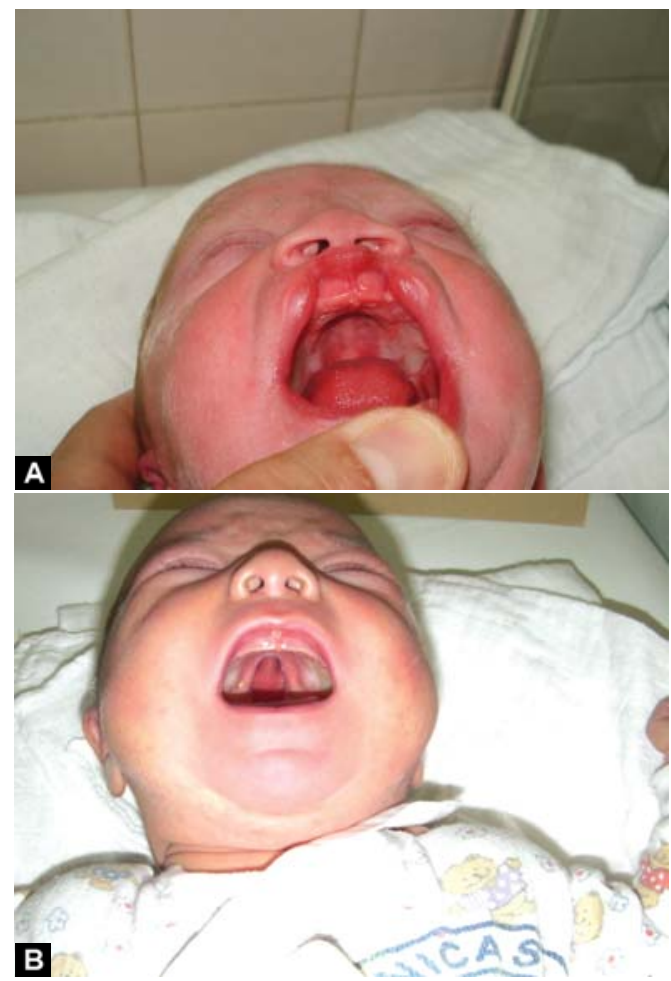

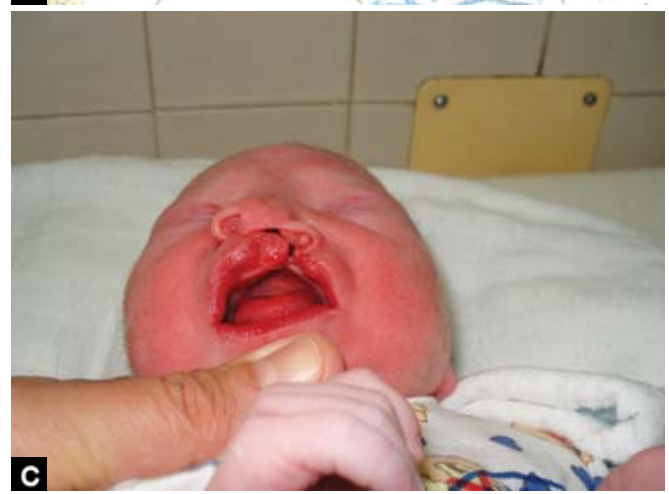

Figs 12A to C: Postnatal images of: (A) Isolated bilateral cleft lip, $(B)$ is olated cleft of the hard palate, (C) left sided cleft of the lip and palate

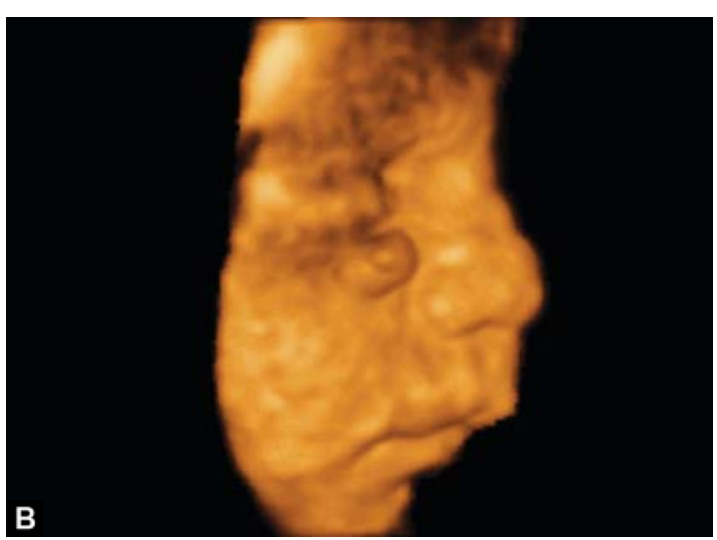

Figs 13A and B: Skin tags: (A) 2D image of the skin tag under the right orbita, (B) 3D surface image of the same skin tag

little clinical significance, constitutes however, an important proof of the sonographers professional competence in the eyes of the child's parents.

\section{Gastrointestinal Tract}

Recently rapid progress has been made in the antenatal recognition and diagnosis of gastrointestinal malformations. 


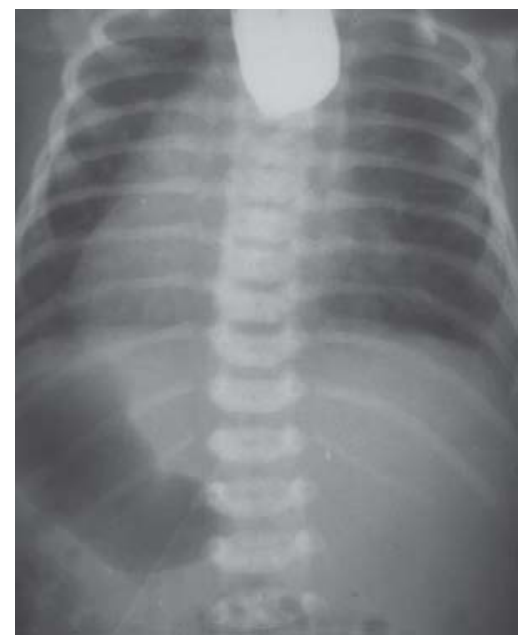

Fig. 14: X-ray of the esophageal atresia with tracheoesophageal fistula in newborn with situs viscerum inversus (dextrocardia, stomach on the right side, esophagus ending in a blind-ended pouch)

Their prevalence is rather high being 17.27 per 10,000 births in Europe. ${ }^{29}$ A ntenatal detection of potentially correctable major gastrointestinal anomalies may be life-saving since, appropriate prenatal preparation may be made for medical and surgical care of the newborn. ${ }^{49}$

The fetal gastrointestinal tract is the most common site of surgically correctable fetal malformations detected by ultrasound. Early detection of esophageal atresia (Fig. 14 postnatal $X$-ray finding of esophageal atresia associated with situs viscerum inversus) (prevalence rate 2.38 per 10,000), duodenal atresia and/or jejunal atresia (prevalence rate of 1.29 per 10,000$),{ }^{29}$ allows planning of delivery and subsequent postnatal corrective surgery in the best equipped available center and in the most suitable conditions. This is certainly the most important advantage. ${ }^{49}$

\section{Esophageal Atresia with or without $F$ istula}

Polyhydramnios accompanied with very small stomach, valid ultrasound diagnosis with clinical features, successfully suggests the set up of the mentioned diagnosis. ${ }^{50,51}$

\section{Duodenal Atresia and J ejunoileal Atresia}

Doudenal atresia is not a life-threatening condition in the first few hours of life. ${ }^{52,53}$ Immediately after birth it is usually asymptomatic, but later on the important clinical sign is persistent vomiting. ${ }^{54} \mathrm{~A}$ typical $\mathrm{X}$-ray image is presented by 'double-bubble' sign of total duodenal obstruction. ${ }^{55}$

A ntenatal diagnosis of jejunoileal atresia in all fetuses was made on the basis of typical findings of polyhydramnios and several dilated loops of fluid-filled intestine in the fetal abdomen. ${ }^{56}$ In the case of jejunal atresia, the parents should be informed of the possibility of an associated apple peel with the short bowel syndrome, which could be often followed by intestinal failure-associated liver disease. ${ }^{57,58}$

Some intestinal obstructions could possibly be caused by meconium ileus with presence of cystic fibrosis as possible causal condition. ${ }^{59,60}$ A norectal malformations are usually diagnosed late in pregnancy or in the early neonatal period, which is not influencing typical treatment of these malformations. ${ }^{61}$ Early in utero antenatal detection of gastrointestinal malformations is very important because in antenatally unrecognized cases, surgical management of neonatal intestine obstruction may be compromised by delayed diagnosis and, consequently complicated by vomiting, electrolyte imbalance, aspiration, sepsis, peritonitis due to intestinal perforation, or bowel gangrene in cases of intestinal volvulus. ${ }^{62}$ If corrective surgery is not performed, gastrointestinal obstruction will ultimately lead to death of the neonate.

\section{Abdominal Wall Defects \\ (Omphalocele and Gastroschisis)}

The most frequent congenital abdominal wall defects are omphalocele (Figs 16A and B, 17A to D) and gastroschisis (Figs 15, 18A and $B$, and 19). In both malformations, the abdominal content is placed outside the abdomen through abdominal wall defect with membrane in omphalocele and without membrane in gastroschisis. ${ }^{63-71}$ B oth are frequently detected prenatally due to routine maternal serum screening and fetal ultrasound. Prenatal diagnosis may influence timing, mode and location of delivery. Prognosis for gastroschisis is primarily determined by the degree of bowel injury, whereas prognosis for omphalocele is related to the number and severity of associated anomalies and the karyotype. The surgical management of both conditions consists of closure of the abdominal wall defect, while minimizing the risk of injury to the abdominal viscera either through direct trauma or due to increased intra-abdominal pressure. ${ }^{63-71}$ Options include primary closure or a variety of staged approaches. Long-term outcome is favorable in most cases; however, significant associated anomalies (in the case of omphalocele) or intestinal dysfunction (in the case of gastroschisis) may result in severe morbidity and mortality. ${ }^{64}$

Gastroschisis shows a normal insertion of the umbilical cord, with the abdominal wall defect and herniation of bowel occurring most often on the right side of the umbilicus. ${ }^{69}$

Consequently, there is no covering membrane. Differentiation of these two abdominal entities can be successful using 3D-color Doppler ultrasound but it is not critical, as management decisions for delivery of the fetus 


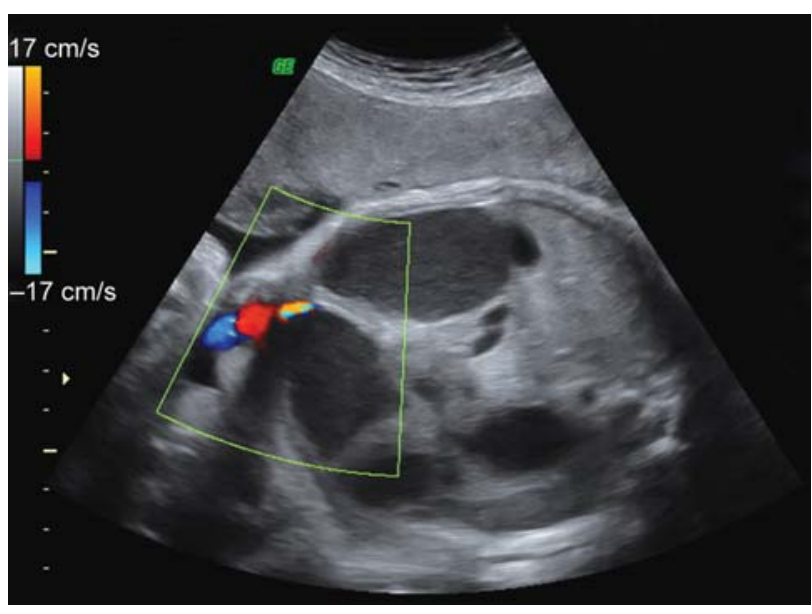

Fig. 15: Gastroschisis dilated small intestine loops due to intestinal inflammatory stenosis and necrosis
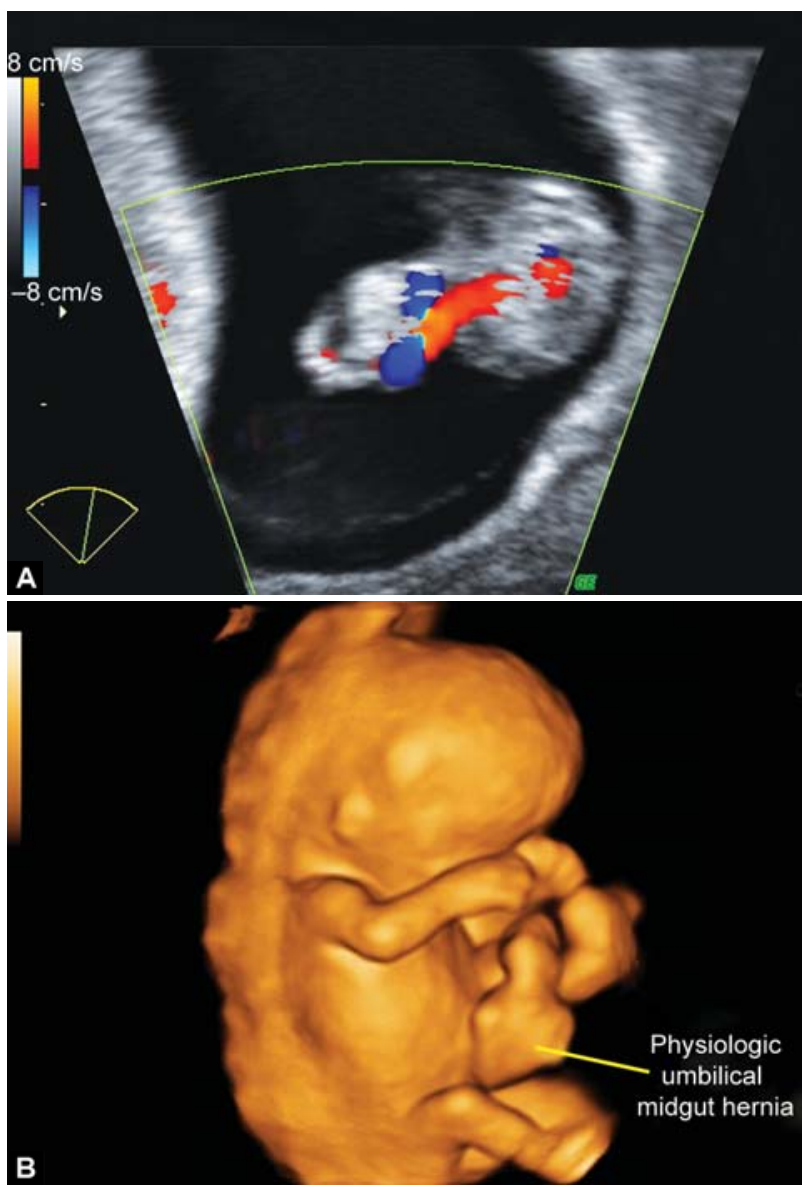

Figs 16A and B: 'Physiological' umbilical herniation in the early fetal period: (A) B-mode with color Doppler, (B) 3D surface rendered image

are the same for both. M anagement of gastroschisis has shifted from early primary closure to preformed silo placement and delayed closure. The change in management strategy has resulted in prolonged intensive care unit stay and time to full feeds but reduced postoperative hernias and wound infections. M ost newborns need only one operation for definitive surgical treatment. ${ }^{67,68}$
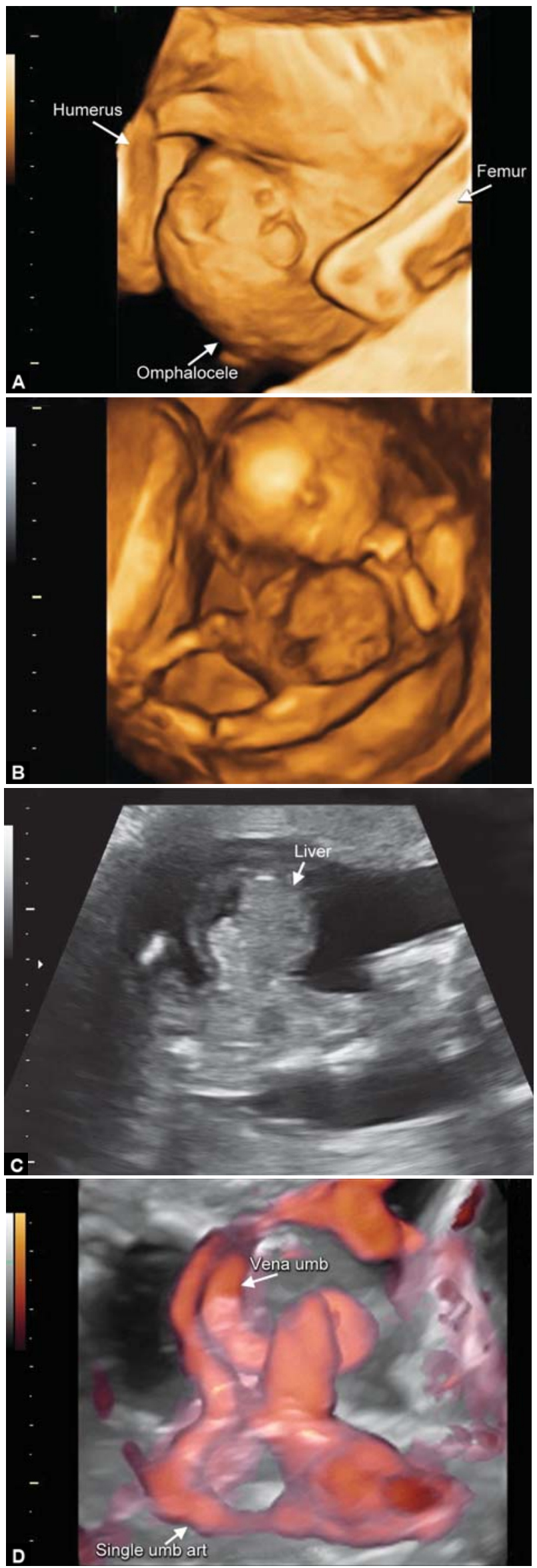

Figs 17A to D: Omphalocele work up with 2D, 3D, and 3D glass body plus power Doppler 


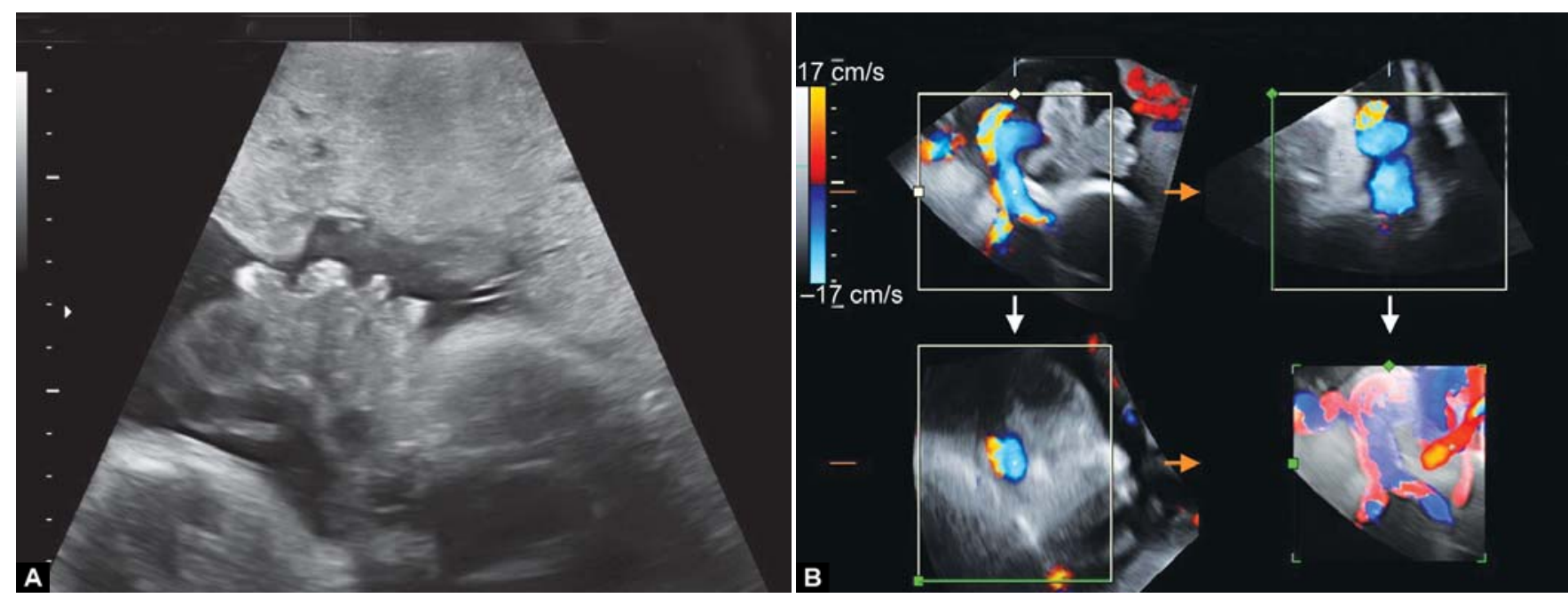

Figs 18A and B: Gastroschisis: (A) B-mode and (B) multiplanar rendering plus color Doppler for demonstration of free bowel loops and assessment of topography of abdominal wall defect and umbilicus

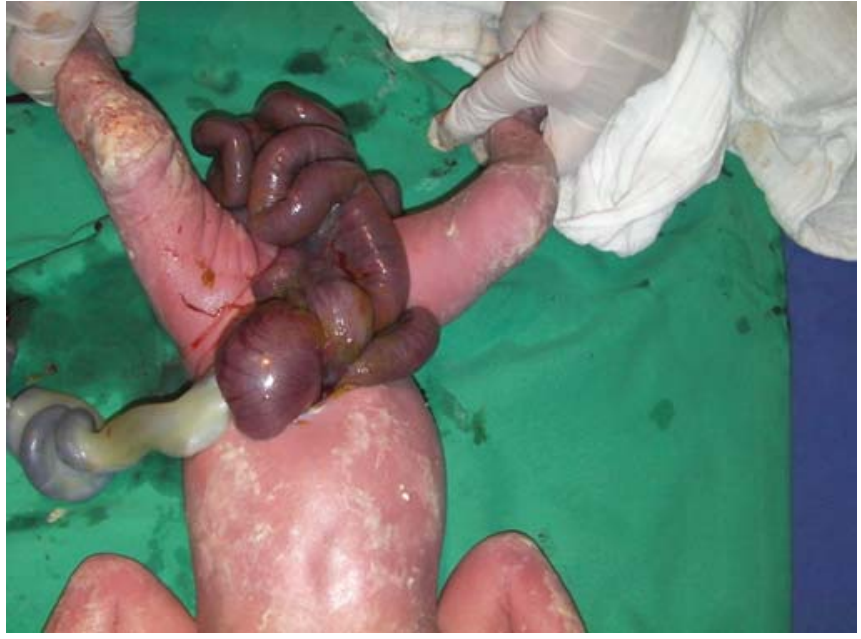

Fig. 19: Postnatal appearance of gastroschisis
Ultrasound was quite accurate in visualizing this abdominal wall defects. ${ }^{63,68}$ Prompt surgical repair was performed in all newborn babies and all had normal neonatal development. Due to a small abdominal cavity and large defect of the abdomen, the abdominal wall defect together with eviscerated intestines is covered by a plastic bag which will enable intestines to be gradually pushed back into the abdominal cavity. Immediately after birth, the baby will be prepared for surgical intervention, to be performed with primary closure using Dacron prosthesis. ${ }^{69-71}$

\section{Congenital Diaphragmatic Hernia (CDH)}

Prevalence rate of congenital diaphragmatic hernia (CHD) in Europe is 2,71 per 10,000 births. ${ }^{29}$ Overhalf of the cases
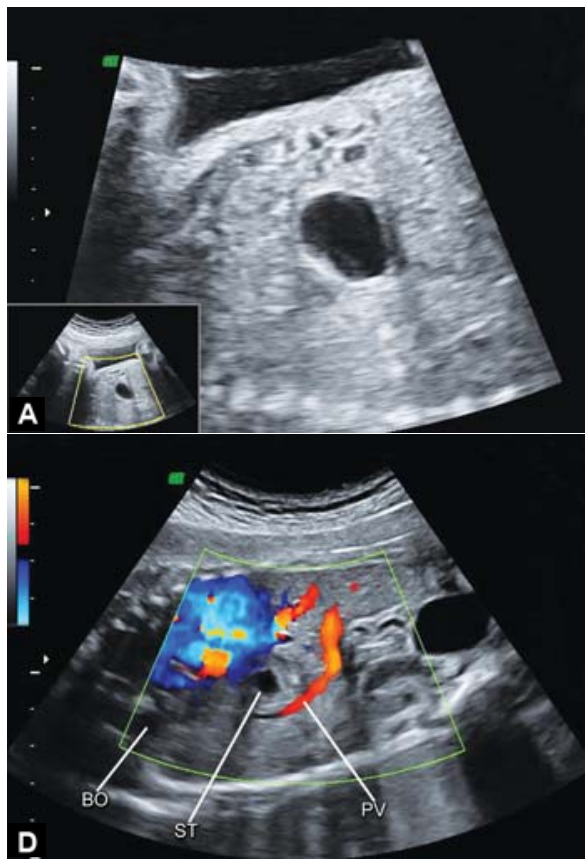
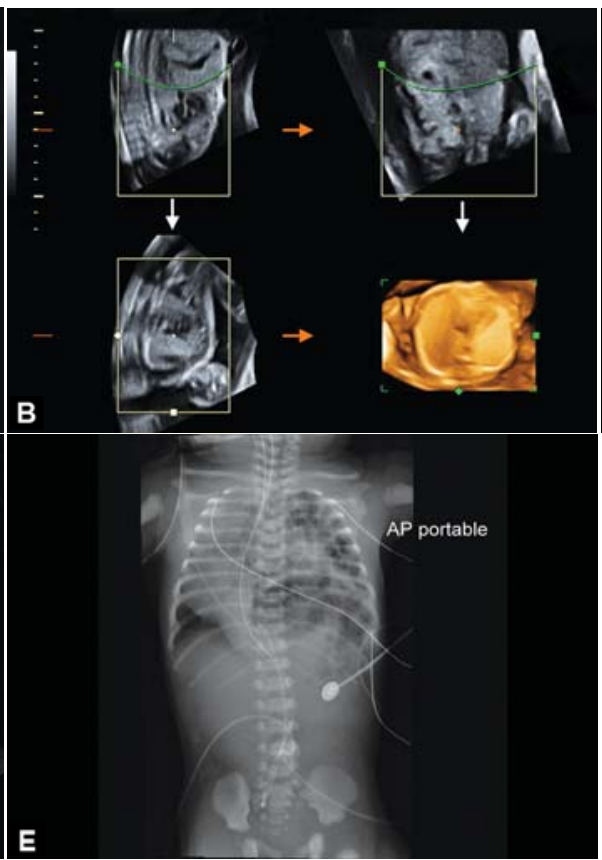

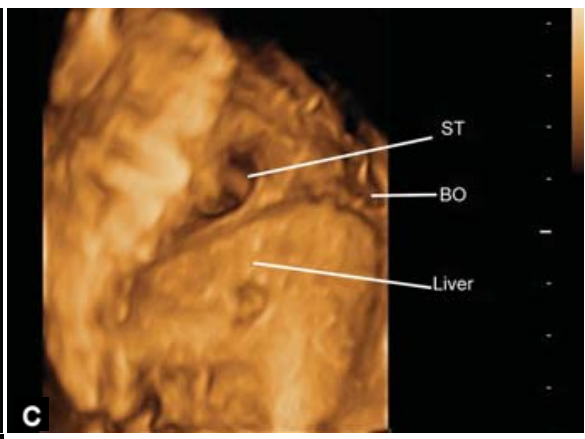

Figs $20 \mathrm{~A}$ to $\mathrm{E}$ : Left congenital diaphragmatic hernia (Bochdalek) in which intestine (BO) and stomach (ST) have herniated into the left chest $(A$ to $C)$. The abnormal position of the portal vein (PV) below the diaphragm confirms the presence of liver herniation (D). Postnatal X-ray $(E)$ 
of congenital diaphragmatic hernia (Figs 20A to $\mathrm{E}$ ) are diagnosed prenatally. ${ }^{72}$ Prenatal assessment aims to rule out associated anomalies in order to make individual prognosis. $^{72}$ Prediction of outcome is based on measurements of lung size and vasculature as well as on liver herniation. ${ }^{72}$ Visceral herniation into the thoracic cavity during the critical period of lung development when bronchi and pulmonary arteries undergo branching at 5 to 16 weeks, leads to decreased bronchial branching, pulmonary hypoplasia, truncation of the pulmonary arterial tree and to dysfunctional surfactant postpartum. ${ }^{72}$ Etiologically defective migration of muscle and nerve cell precursors to the diaphragm during its formation is considered the cause of $\mathrm{CDH}$. The diaphragm develops anteriorly as a septum between the heart and liver, and then grows posteriorly. Final closure is at the left Bochdalek foramen between 8 and 10 weeks gestational age (GA). B owel migrates from yolk sac to abdominal cavity at 10 weeks. If bowel arrives before the foramen closes then hernia can occur. ${ }^{73}$

$M$ any newborn babies affected by $C D H$ die because of respiratory insufficiency caused by pulmonary hypoplasia. ${ }^{72}$ Prenatal intervention percutaneous fetal endoscopic tracheal occlusion by a balloon may be offered in those selected fetuses with CHD that have a predicted poor outcome. The aim of this procedure is to reverse the key determinant of survival-pulmonary hypoplasia. The outcome can be predicted by the gestational age at birth, the lung size before and after balloon placement, and whether the balloon has been removed prenatally. Currently, the added value of prenatal intervention is being investigated in the tracheal occlusion to accelerate lung growth (TOTA L) European and N orth A merican trial. ${ }^{72} \mathrm{High}$ mortality rate $(50-80 \%)$ of the newborns with CHD suffering severe respiratory insufficiency at birth was significantly reduced by recent improvements of newborn transportation, breathing assistance and intensive care. Introduction of extracorporeal membrane oxygenation (ECMO) enables buying time for further lung growth and maturation. Survival rate is improved if hernia repair is delayed to allow resolution of early pulmonary insufficiency and acute pulmonary hypertension. ${ }^{74}$

A subset of fetuses likely to die in the postnatal period is eligible for a fetal intervention that can promote lung growth. Two randomized trials have shown that fetal surgery using open anatomical repair or tracheal occlusion via hysterostomy has no benefit. Since then, a percutaneous fetoscopic technique has been introduced, which has been shown to be safe and seems to improve survival when compared to historical controls. ${ }^{72,75}$ In utero fetoscopic treatment by means of tracheal balloon occlusion (FETO) obstructs normal egress of lung fluid, hereby increasing transpulmonic pressure, to create large fluid filled lungs which are supposed to improve lung growth. Lack of lung expansion 2 to 7 days after tracheal occlusion is considered poor prognostic sign. ${ }^{75}$

Postnatal treatment of neonate with suspected CHD is very important because ventilation with bag and mask can cause severe damage to the hypoplastic lungs, and acute shift of the mediastinum by inflating stomach, causing further reduction of survival rates. Immediate endotracheal intubation together with orogastric tube insertion is the method of choice for the resuscitation of those newborns with life-threatening congenital defect. ${ }^{74}$

\section{Congenital Pulmonary Anomalies}

Congenital cystic adenomatoid malformation (CCAM) and bronchopulmonary sequestration (BPS) are major embryonic pulmonary developmental anomalies. ${ }^{76,77}$ Congenital cystic lesions of the lung in children are uncommon but potentially life-threatening and warrant an urgent diagnostic work up. Pulmonary sequestration (PS), CCAM, congenital lobar emphysema (CLE), and bronchogenic cyst (BC) (prenatal finding Figs 21A and B) are the four major congenital cystic lesions, but they share similar embryologic and clinical characteristics. A meaningful percentage of CCAM joins to PS and CLE; instead the BC is generally isolated. ${ }^{76,77}$

The treatment of these lesions is surgical: CCAM (type I-II) and CLE should be treated promptly in newborns for respiratory distress and pneumothorax, early surgical resection within 1 month of age is safe in symptomatic patients. CCAM (type II) and BC become symptomatic gradually and expose to degenerative risk; intralobar PS generally becomes symptomatic and surgery prevents the risk of infections. Extralobar PS and the asymptomatic BC are not exempted by surgical approach whenever, accidentally described as masses of uncertain nature. A symptomatic cysts in children should be resected, to avoid later complications of the cysts, which could make operation more difficult. Conservative anatomic resections should be attempted to preserve functional lung tissue. Careful histological examination of the resection specimen is mandatory to identify occult malignancy. ${ }^{76,77}$

\section{Congenital Heart Defects}

CHD have an overall incidence of about $1 \%$ in live-born infants, and account for $20 \%$ of all stillbirths and $30 \%$ of neonatal deaths dueto congenital anomalies. The prevalence rate in Europe is 80.62 per 10,000 of which 20.15 are severe 


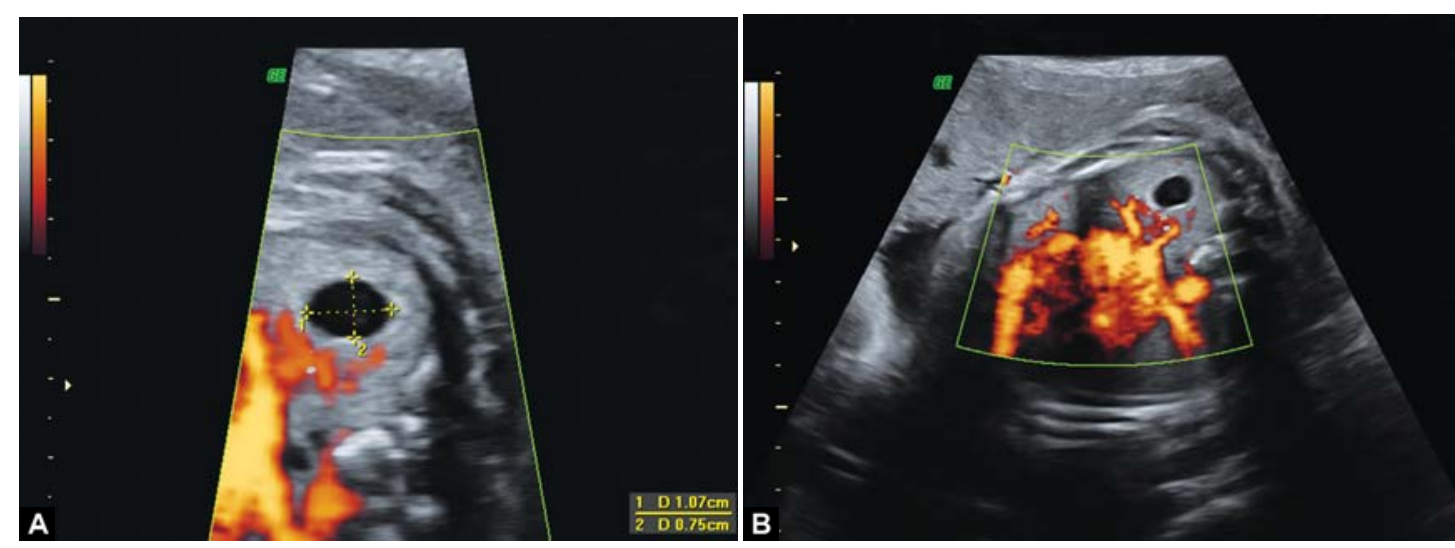

Figs 21A and B: Bronchogenic lung cyst: (A) 2D, (B) power Doppler assessment
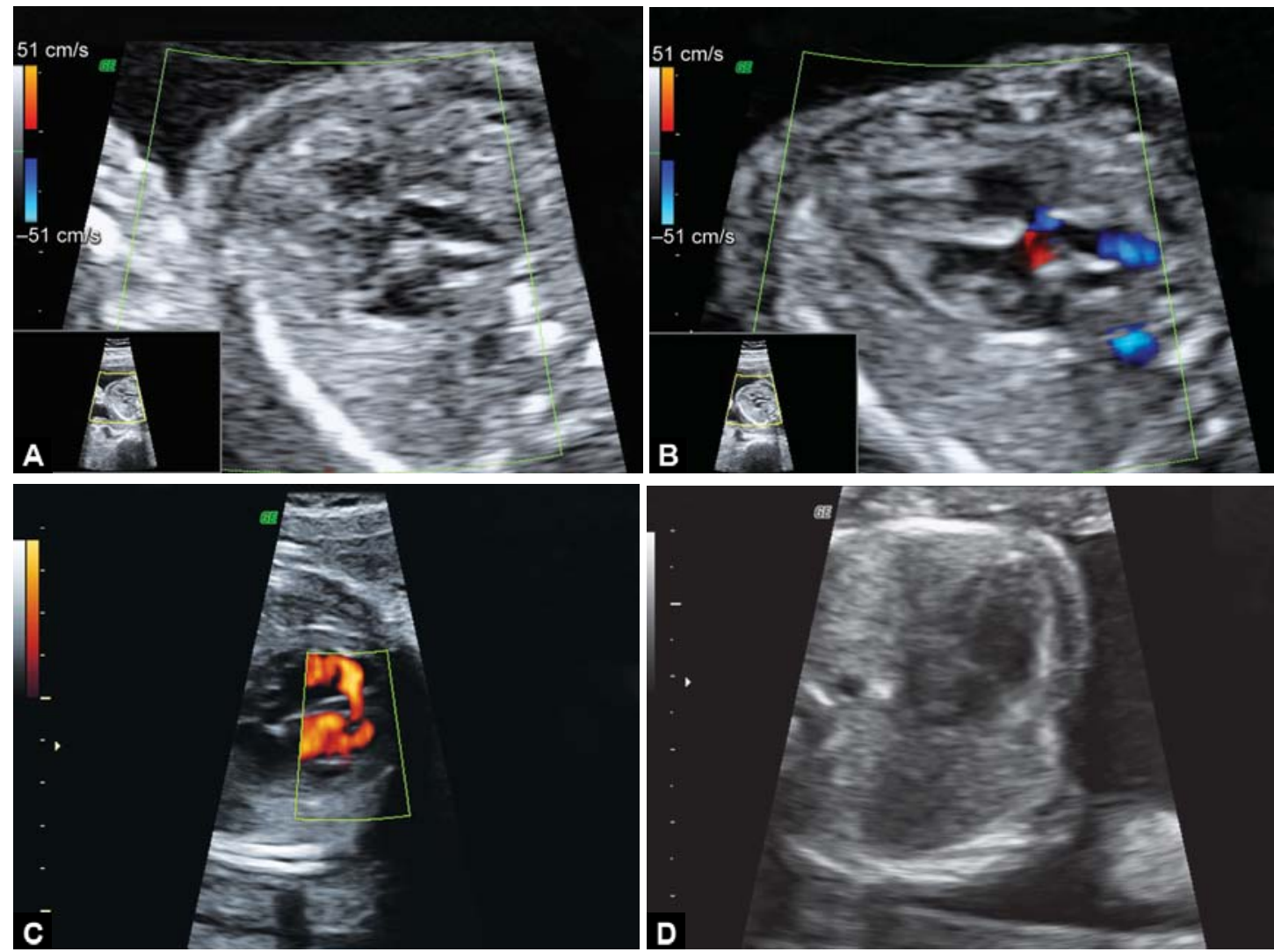

Figs 22A to D: (A) Membranous ventricular septal defect (VSD), (B) color Doppler: membranous ventricular septal defect (VSD), (C) power Doppler: muscular VSD, (D) hypoplastic left heart syndrome (four chamber view)

CHD. The etiology of CHD includes maternal diseases, such as diabetes mellitus, phenylketonuria, exposureto substances (anticonvulsants, lithium), infections (parvovirus, rubella), chromosomal anomalies (trisomies 21 and 18) and specific mutantgene defects. However, therearemany unknowncauses. The for aneuploidy of the fetus with CHD is $30 \% .{ }^{78-80}$ The recurrence risk of cardiac anomalies in the absence of a known genetic syndrome is 2 to $4 \%$, and with two previously affected siblings it is 10\%. ${ }^{80} \mathrm{M}$ ajor $\mathrm{CHD}$ have an estimated prevalence of 2 to 4 per 1,000 live births and are either lethal or require surgical repair or intervention within the first year of life. ${ }^{80}$ Thedivision of the heartinto afour-chamber structure is achieved by 8 weeks of gestation. Itwas possi ble 16 years ago at gestational age of 13 to 15 weeks using a high-resolution transvaginal transducer to obtain satisfactory images of the four-chamber view and the outflow tracts in the majority of fetuses (Figs 22A to D prenatal diagnosis of congenital heard defects). ${ }^{81}$ 


\section{Management of Surgically Correctable Fetal Anomalies}

\section{Prenatal Management}

The goal is to offer noninvasive screening for fetal malformations and fetal aneuploidy (trisomy 13, 18, 21) to all pregnant women. Invasive prenatal diagnosis would be offered to women who screen above a set risk cut off level on noninvasive screening or to pregnant women whose personal, obstetrical, or family history places them at increased risk. ${ }^{82}$ Currently available noninvasive screening options include maternal age combined with one of the following: (1) First-trimester screening (nuchal translucency, maternal age, and maternal serum biochemical markers), (2) Second-trimester serum screening (maternal age and maternal serum biochemical markers), or (3) 2-step integrated screening, which includes first- and second- trimester serum screening with or without nuchal translucency (integrated prenatal screen, serum integrated prenatal screening, contingent and sequential). ${ }^{82} \mathrm{~W}$ e found useful recommendations from Canada which are given as citation. $^{82}$

1. All pregnant women in Canada, regardless of age, should be offered, through an informed counseling process, the option of a prenatal screening test for the most common clinically significant fetal aneuploidies in addition to a second-trimester ul trasound for dating, assessment of fetal anatomy, and detection of multiples (level of evidence: I-A).

2. Counseling must be nondirective and must respect a woman's right to accept or decline any or all of the testing or options offered at any point in the process (III-A).

3. Maternal age alone is a poor minimum standard for prenatal screening for aneuploidy, and it should not be used a basis for recommending invasive testing when noninvasive prenatal screening for aneuploidy is available (II-2A).

4. Invasive prenatal diagnosis for cytogenetic analysis should not be performed without multiple marker screening results except for women who are at increased risk of fetal aneuploidy (a) because of ultrasound findings, (b) because the pregnancy was conceived by invitrofertilization with intracytoplasmic sperm injection, or (c) because the woman or her partner has a history of a previous child or fetus with a chromosomal abnormality or is a carrier of a chromosome rearrangement that increases the risk of having a fetus with a chromosomal abnormality $(\mathrm{II}-2 \mathrm{E})$.
5. A t minimum, any prenatal screen offered to $C$ anadian women who present for care in the first-trimester should have a detection rate of $75 \%$ with no more than a $3 \%$ false-positive rate. The performance of the screen should be substantiated by annual audit (III-B).

6. The minimum standard for women presenting in the second-trimester should be a screen that has a detection rate of $75 \%$ with no more than a $5 \%$ false-positive rate. The performance of the screen should be substantiated by annual audit (III-B).

7. First-trimester nuchal translucency should be interpreted for risk assessment only when measured by sonographers or sonologists trained and accredited for this service and when there is ongoing quality assurance (II-2A), and it should not be offered as a screen without biochemical markers in singleton pregnancies (I-E).

8. Evaluation of the fetal nasal bone in the first-trimester should not be incorporated as a screen unless it is performed by sonographers or sonologists trained and accredited for this service and there is ongoing quality assurance (II-2E).

9. For women who undertake first-trimester screening, second-trimester serum alpha fetoprotein screening and/or ultrasound examination is recommended to screen for open neural tube defects (II-1A).

10. Timely referral and access is critical for women and should be facilitated to ensure women are able to undergo the type of screening test they have chosen as first-trimester screening. The first step of integrated screening (with or without nuchal translucency), contingent or sequential screening are performed in an early and relatively narrow time window (II-1A).

11. Ultrasound dating should be performed, if menstrual or conception dating is unreliable. For any abnormal serum screen calculated on the basis of menstrual dating, an ultrasound should be done to confirm gestational age (II-1A).

12. The presence or absence of soft markers or anomalies in the 18 to 20-week ultrasound can be used to modify the a priori risk of aneuploidy established by age or prior screening (II-2B).

13. Information, such as gestational dating, maternal weight, ethnicity, insulin-dependent diabetes mellitus, and use of assisted reproduction technologies should be provided to the laboratory to improve accuracy of testing (II-2A).

14. Health care providers should be aw are of the screening modalities available in their province or territory (III-B). 
15. A reliable system needs to be in place ensuring timely reporting of results (III-C).

16. Screening programs should be implemented with resources that support audited screening and diagnostic laboratory services, ultrasound, genetic counseling services, patient and health care provider education, and high quality diagnostic testing, as well as resources for administration, annual clinical audit and data management. In addition, there must be the flexibility and funding to adjust the program to new technology and protocols (II-3B).

In order to optimize fetal outcome, there should be an interdisciplinary approach, including special ists in maternalfetal medicine, neonatology, genetics, pediatric surgery and pediatric cardiology. ${ }^{83-85}$ Social work services may provide important support to the family before as well as after birth. Such team approach is the best way to address the important issues of where, when, and how the infant should be delivered, as well as the role of invasive fetal therapy. ${ }^{85}$

\section{Postnatal Counseling and Management}

Congenital anomalies are among leading causes of infant mortality (Fig. 23) and an important contributor to childhood and adult morbidity. It is estimated that about 20 to $30 \%$ of neonatal deaths could be attributed to major congenital malformations. ${ }^{86} \mathrm{M}$ ajor congenital anomalies are abnormalities which are severe enough to reduce life expectancy or compromise normal function. ${ }^{6}$ If major malformations cause stillbirth or infant death in more than $50 \%$ of cases, they are considered lethal. If newborn infant with major malformation can not survive without medical intervention, than malformation is considered severe. ${ }^{6}$

Fetuses and neonates with congenital anomalies can be divided into six groups: ${ }^{87}$

1. Those who have the potential for total recovery;

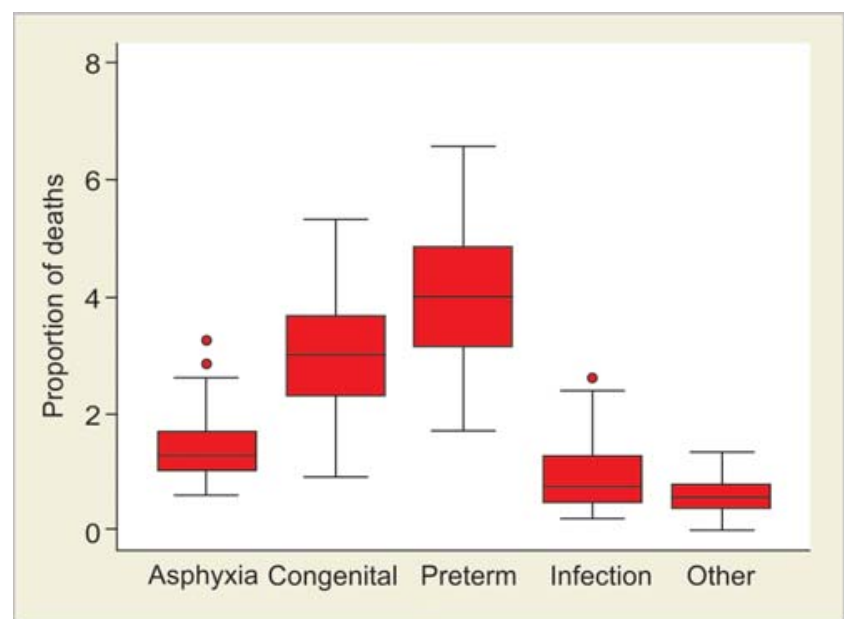

Fig. 23: Box plots showing the proportional distribution of causes of neonatal mortality for the vital registration data (44 countries) ${ }^{86}$
2. Those with anomalies that would allow for a nearly normal life;

3. Those with malformations requiring permanent supervision and/or medical care;

4. Those with somatic rest defect and subnormal mental development;

5. Those with serious somatic and mental damage; and

6. Those with anomalies that are incompatible with life.

The physician should lower the anxiety of the parents, should follow the morals of a civilized society, should act according to the law, and finally, should convince himself to be a solution to a problem and not to be a cause of any ${ }^{87}$

A ccording to the A merican A cademy of Pediatrics, there are three possibilities concerning the treatment with intensive care in decision-making process based on the infant's prognosis: ${ }^{88}$

- The intensive care is indicated, if survival is likely and the risk of severe morbidity is low.

- The intensive care is not indicated, if the survival is not likely and would be accompanied by severe unacceptable morbidity and suffering.

- In some cases the situation could be in between those two situations and prognosis is not certain, but very likely to be very poor. In that situation parental desires should determine the treatment approach.

In the first situation of ' normality', where child affected with deformation is interpreted as 'normal child', which means that the disorder is curable and the infant can lead a normal life thereafter. This group of infants includes those with single defects, such as cleft lip, some congenital heart defects, pyloric stenosis, hexodactyly, etc. Parents should be informed that the child is normal, with a small problem which is curable and can be easily and adequately solved. The statement that the infant is normal is very important as well as the information that the condition is correctable. Such approach to the counseling can help parents with realistic acceptance of the problem. In case when physicians fail to make acceptance of infant's condition, than relations between parents and their child may develop in two undesirable directions: Rejection or overprotection. ${ }^{88}$

In the second group when dealing with severely malformed infant-like anencephaly, severe neural tube defects, hydranencephaly, holoprosencephaly, the trisomy 18 and 13 syndrome, the $4 p$-syndrome, the M eckel-G ruber or Potter syndrome, the physician must give parents the option of no medical intervention. ${ }^{88} \mathrm{~A} / \mathrm{l}$ mentioned disorders are severely limiting infant's capacity to survive and function even with full medical support including intensive care $^{88}$ The doctor should say that even if the life will be 
preserved for some time, the baby has no capacity for continued survival. In the case of intervention the functional capability of the baby will be very limited. ${ }^{88}$ The physician should state that the kindest approach to the infant is that of no medical intervention, and ask for the permission for such an approach. In such way parents are informed about the basic course of the problem, helped to interpret the situation, and given the option of no medical intervention in the best interest of the child. ${ }^{88}$ They should be aware that the baby will be provided with compassionate care and that suffering will be minimal. Sometimes when parents are faced with end-of-life decisions, they will need psychological or social worker help to overcome their problem. ${ }^{89}$ Parental complaints are more likely to occur due to misunderstanding, confusion and tension among staff and parents as a result of a failure to have in place or to implement agreed protocols. ${ }^{90}$

When dealing with intermediate situation, the counseling of the parents is very complicated and individualized, depending on the nature and the severity of the handicap. The accurate information is again very important, including facts relative to the cause of the problem, the usual range of functional and other limitations, and what can be done in order to help the child to adapt to the problem. In this situation the parents should be helped to accept their child with the problem, informing them that there are other families with the same or similar problems. ${ }^{89-91}$

Generally, this counseling process is very hard working and time consuming. Any medical professional who is counseling parents of malformed new borns should be aware that parents may need several meetings to accept the situation and to understand it. ${ }^{89-91}$ Sometimes the same information rephrased is well-accepted, and on another occasion the parents do not even notice the problem. Some parents are almost incapable of accepting a handicapping disorder of their child, while the others can develop deep parental love for a malformed and handicapped child. $88,89,91$

\section{CONCLUSION}

A ntenatal diagnosis together with the improvement of surgical and postoperative care of newborns with severe surgically correctable congenital anomalies enabled better survival of live-born infants and more effective prenatal prevention in case of preventable anomalies. Nevertheless, congenital malformations continue to be important cause of perinatal mortality rate in developed and in developing countries. In order to optimize fetal outcome, there should be an interdisciplinary approach, including specialists in maternal-fetal medicine, neonatology, genetics, pediatric surgery, pediatric cardiology and neurosurgery. More attention should be paid to the primary, secondary and tertiary prevention of surgically correctable congenital anomalies whenever possible.

\section{REFERENCES}

1. K alter H. Congenital malformations: A $n$ injury into classification and nomenclature. J M ed Genet 1998;35:661-65.

2. Committee on F etus and N ewborn. N oninitiation or withdrawal of intensive care for high-risk newborns. Pediatrics 2007;119:401-03.

3. Kurjak A, Kirkinen P, Latin V, Rajhvajn B. Diagnosis and assessment of fetal malformations and abnormalities by ultrasound. J Perinat M ed 1980;8:219-35.

4. Kurjak A, Latin V, M andruzzato G, D'A ddario V , Rajhvajn B. $U$ Itrasound diagnosis and perinatal management of fetal genitourinary abnormalities. J Perinat M ed 1984;12:291-312.

5. K urjak A, Gogolja G, K ogler A, L atin V, Rajhvajn B. Ultrasound diagnosis and perinatal management of surgically correctable fetal malformations. Ultrasound M ed Biol 1984;10:443-55.

6. Kumar P, Burton BK. Malformations: Evidence-based evaluation and management. N ew Y ork: M cGraw-Hill M edical, 2008.

7. Nelson C. Editorial comment. J U rol 2009;182(Suppl 4):1848.

8. Gordon I, Riccabona M. Investigating the newborn kidney: Update on imaging techniques. Seminars Neonatol 2003;8: 269-78.

9. $Y$ ang $Y$, H ou $Y, N$ iu ZB, W ang CL. Long-term follow-up and management of prenatally detected, isolated hydronephrosis. J Pediatr Surg 2010;45:1701-06.

10. Herndon $C D, K$ itchens $D M$. The management of uteropelvic junction obstruction presenting with prenatal hydronephrosis. Scientific W orld J ournal 2009;9:400-03.

11. Dar P, Sachs GS, C arter SM , F erreira JC, N itowsky H M, Gross S). Prenatal diagnosis of Bardet-Biedl syndrome by targeted second-trimester sonography. U Itrasound Obstet Gynecol 2001;17:354-56.

12. Schaefer E, Zaloszyc A, Lauer J, Durand M, Stutzmann F, Perdomo-Trujillo $Y$, et al. Mutations in SDCCA G8/NPHP10 cause $B$ ardet- $B$ iedl syndrome and are associated with penetrant renal disease and absent polydactyly. Mol Syndromol 2011;1:273-81.

13. Dippell J, Varlam DE. Early sonographic aspects of kidney morphology in B ardet-Biedl syndrome. Pediatr N ephrol 1998 Sep; 12(7):559-63.

14. Cassart M, Eurin D, Didier F, Guibaud L, A vni EF. A ntenatal renal sonographic anomalies and postnatal follow-up of renal involvement in Bardet-Biedl syndrome. Ultrasound Obstet Gynecol 2004;24:51-54.

15. A ydogdu $0, B$ urgu B, Soygur T. Predictors of surgical outcome in children with vesi coureteral reflux associated with paraureteral diverticula. U rology 2010;76:209-14.

16. Golbus M S, Harrison M R, Filly RA, et al. In utero treatment of urinary tract obstruction. Am J Obster Gynecol 1982;142: 383-88.

17. T sai $Y L$, Seow $K M, Y$ ieh $C H, C$ hong $K M$, H wang JL, et al. Comparative study of conservative and surgical management for symptomatic moderate and severe hydronephrosis in pregnancy: A prospective randomized study. A cta Obstet Gynecol Scand 2007;86:1047-50. 
18. Bajpal M, Bal CS, Tripathi M, Kalaivani M, Gupta AK. Prenatally diagnosed unilateral hydronephrosis: Prognostic significance of plasma rennin activity. J U rol 2007;178: 2580-84.

19. Ross SS, Kardos S, K rill A, Bourland J, Sprague B, et al. Observation of infants with SFU grades 3-4 hydronephrosis: Worsening drainage with serial diuresis renography indicates surgical intervention and helps prevent loss of renal function. J Pediatr U rol 2011;7:266-71.

20. Castagnetti M, Novara G, B eniamin F, V ezzu B, Rigamonti W, et al. Scintigraphic renal function after unilateral pyeloplasty in children: A systemic review. BrJ U rol 2008;102:862-68.

21. Gritzmann N, Czembirek H, K arnel F. Pulsed duplex sonography in the detection of lower pole arteries in hydronephrosis. Radiologe 1986;26:503-05.

22. Nouralizadeh A, Simforoosh N, B asiri A, Tabibi A, Soltani M H, $\mathrm{K}$ ilani $\mathrm{H}$. Laparoscopic management of ureteropelvic junction obstruction by division of the aberrant vein and cephalad relocation of the crossing artery: A long-term follow-up of 42 cases. J Endourol 2010;24:987-91.

23. Dally EA, Raman A, W ebb NR, Farnsworth Rh. Unilateral multicystic dysplastic kidney with progressive infundibular stenosis in the contralateral kidney: Experience at 1 center and review of literature. J U rol 2011;186:1053-58.

24. Eble JN, Sauter G, Epstein JI, Sesterhenn IA. Tumors of the urinary system and male genital organs: Pathology and genetics. Geneva: World Health Organization, 2004.

25. Kelner M, Droulle P, Didier F, Hoeffel JC. The vascular 'ring' sign in mesoblastic nephroma: Report of two cases. Pediatr Radiol 2003;33:123-28.

26. Leclair M D, El-Ghoneimi A, A udry G, Ravasse P, M oscovici J, Heloury Y, French Pediatric U rology Study Group. The outcome of prenatally diagnosed renal tumors. J U rol 2005; 173:186-89.

27. Oi S, Inagaki T, Shinoda M , T akahashi S, O no S, et al. G uideline for management and treatment of fetal and congenital hydrocephalus: Center of Excellence. Fetal and congenital hydrocephal us: Top $10 \mathrm{~J}$ apan guidelines 2011. Childs N erv Syst 2011;27:1563-70.

28. Simon TD, Whitlock K B, Riva-Cambrin J,K estle JR, Rosenfeld $M$, Dean JM, Holubkov R, Langley M, M ayer-Hamblett N. Association of intraventricular hemorrhage secondary to prematurity with cerebrospinal fluid shunt surgery in the first year following initial shunt placement. J Neurosurg Pediatr 2012;9:54-63.

29. http://ww w . eurocat-netw ork. eu/accessprevalencedata/ preval encetables

30. Cavalheiro S, M oron A F, A Imodin CG, Suriano IC, Hisaba V, et al. Fetal hydrocephalus. Childs Nerv Syst 2011;27:1575-83.

31. Girard NJ . M agnetic resonance imaging of fetal devel opmental anomalies. Top M agn Reson Imaging 2011;22:11-23.

32. Stranjalis G, K alamatianos T, K outsarnakis C, L oufardaki M, Stavrinou L, Sakas DE. Twelve-year hospital outcomes in patients with idiopathic hydrocephalus. Acta Neurochir 2012;113 (suppl):115-17.

33. M cGirt M J, W oodworth G, Coon AL, Thomas G, Williams M A, Rigamonti D. Diagnosis, treatment, and analysis of long-term outcomes in idiopathic normal-pressure hydrocephalus. Neurosurgery 2008;62 (Suppl 2):670-77.

34. Notarianni C, V annemreddy $P, C$ aldito $G, B$ ollam $P$, W ylen $E$, Willis B, Nanda A. Congenital hydrocephalus and ventriculo- peritoneal shunts: Influence of etiology and programmable shunts on revisions. J Neurosurg Pediatr. 2009;4:547-52.

35. M ahajan C, Rath GP, Dash HH, Bithal PK. Perioperative management of children with encephalocele: $A n$ institutional experience. J Neurosurg A nesthesiol 2011;23:352-56.

36. Alexiou GA, Sfakianos G, Prodromou N. Diagnosis and management of cephaloceles. J Craniofac Surg 2010;21: 1581-82.

37. Bulbul A, Can E, Bulbul LG, Cömert S, Nuhoglu A. Clinical characteristics of neonatal meningomyelocele cases and effect of operation time on mortality and morbidity. Pediatr N eurosurg 2010;46:199-204.

38. De Wals P, Tairou F, V an A llen M I, et al. Reduction in neuraltube defects after folic acid fortification in Canada. N Engl J M ed 2007;357:135-42.

39. Gupta AK, Varma DR. V ein of Galen malformations: Review. Neurology India 2004;52:43-53.

40. Li A H, A rmstrong D, B ruggeter KG. Endovascular treatment of vein of $G$ alen aneurysmal malformation: Management strategy and 21-year experience in Toronto.J N eurosurg Pediatr 2011;7:3-10.

41. Lasjaunias P. V ascular diseases in neonates, infants and children: Interventional neuroradiology management. Springer-V erlag Berlin Heidel berg 1997:67-202.

42. Sherer DM, A nyaegbunam A, Onyeije C. A ntepartum fetal intracranial hemorrhage, predisposing factors and prenatal sonography: A review. A m J Perinatol. 1998;15:431-41.

43. Huang Y F, Chen WC, T seng JJ, Ho ES, Chou M M .Fetal intracranial hemorrhage (fetal stroke): R eport of four antenatally diagnosed cases and review of the literature. Taiwan J Obstet Gynecol 2006;45:135-41.

44. Elchalal U, Y agel S, G omori J M , Porat S, B eni-A dani L, Y anai $\mathrm{N}, \mathrm{N}$ adjari M . Fetal intracranial hemorrhage (fetal stroke): Does grade matter? U Itrasound O bstet Gynecol 2005;26:233-43.

45. Ghi T, Simonazzi G, Perolo A, Savelli L, Sandri F, B ernardi B, Santini D, B ovicelli L, Pilu G. O utcome of antenatally diagnosed intracranial hemorrhage: Case series and review of the literature. Ultrasound Obstet Gynecol 2003;22:121-30.

46. Kurjak A, M iskovic $B, A$ miel-Tisson $C, A$ hmed $B, A$ zumendi G, V asilij O, A ndonotopo T, Turudic T, Salihagic-K adic. New scoring system for fetal neurobehavior assessed by three and four-dimensional sonography. J Perinat M ed 2008; 36:73-81.

47. K irbschus A, Gesch D, Heinrich A, Gedrange T. Presurgical nasoalveolar molding in patients with unilateral clefts of lip, alveolus and palate. Case study and review of the literature. J Craniomaxillofac Surg 2006;34 (Suppl 2):45-48.

48. W iggman $K$, Larson $M, L$ arson $O$, Semb $G, B$ rattström $V$. The influence of the initial width of the cleft in patients with unilateral cleft lip and palate related to final treatment outcome in the maxilla at 17 years of age. Eur J Orthod 2012;doi: 10.1093/ejo/ cjr144.

49. De Grazia E, Di Pace M R, Caruso A M , Catalano P, Cimador P. Different types of intestinal atresia in identical twins. J Pediatr Surg 2008;43:2301-04.

50. Houben $\mathrm{CH}$, Curry JI. Current status of prenatal diagnosis, operative management and outcome of esophageal atresia/ tracheoesophageal fistula. Prenat Diagn 2008;28:667-75.

51. Mourali M, Essoussi-Chikhaoui J, Fatnassi A, El Fekih C, Ghorbel S, et al. Prenatal diagnosis of esophageal atresia. Tunis M ed 2001;89:213-14 
Surgically Correctable Fetal Anomalies: Ultrasound Diagnosis and Management

52. Kilbride H, Castor C, A ndrews W. Congenital duodenal obstruction: Timinig of diagnosis during the newborn period. J Perinatol 2010;30:197-200.

53. Choudhry M S, Rahman N, B oyd P, Lakhoo K. Duodenal atresia: A ssociated anomalies, prenatal diagnosis and outcome. Pediatr Surg Int 2009;25:727-30.

54. Rao P. Neonatal gastrointestinal imaging. Eur J Radiol 2006;60:171-86.

55. Y ang HC,. Chen SJ , Liu K L. D ouble bubble sign. Emerg M ed J 2011;28:1084.

56. Ohyama M, Itani $Y$, Ishikawa H, Tanaka $Y$. Is umbilical cord ulcer associated with congenital upper intestinal atresia so rare? Japanese case series and review of the literature. Fetal Diagn Ther 2010;28:236-37.

57. M iraglia R, Catalano P, M aruzzelli L, Riva S, Spada M, A lberti D, Luca A , Gridelli B. B alloon dilatation of postoperative small bow el anastomotic stricture in an infant with apple peel intestinal atresia after serial transverse enteroplasty and jejunoileal anastomosis. J Pediatr Surg 2010;45:e25-28.

58. Lilja HE, Finkel Y, Paulsson M, L ucas S. Prevention and reversal of intestinal failure-associated liver disease in premature infants with short bowel syndrome using intravenous fish oil in combination with omega-6/9 lipid emulsions. J Pediatr Surg 2011;46:1361-67.

59. van der Doef HP, Kokke FT, van der Ent CK, Houwen RH. Intestinal obstruction syndromes in cystic fibrosis: M econium ileus, distal intestinal obstruction syndrome and constipation. Curr Gastroenterol Rep 2011;13:265-70.

60. Paradiso VF, Briganti V, Oriolo L, Coletta R, Calisti A. $M$ econium obstruction in absence of cystic fibrosis in low birth weight infants: A n emerging challenge from increasing survival. Ital J Pediatr 2011;37:55.

61. M irza B, Ijaz L, Saleem M, Sharif M, Sheikh A. A norectal malformations in neonates. A fr J Paediatr Surg 2011;8:151-54.

62. Watanabe T, Nakano M, Y amazawa K, M aeyama K, Endo M . Neonatal intestinal volvulus and preduodenal portal vein associated with situs ambiguus: Report of a case. Surg Today 2011;41:726-29.

63. M ann S, B linman TA, D ouglas W ilson R. Prenatal and postnatal management of omphal ocoele. Prenat Diagn 2008;28;626-32.

64. Christison-Lagay ER, K elleher CM, L anger JC Neonatal abdominal wall defects. Semin Fetal Neonatal Med 2011;16: 164-72.

65. Payne NR, Pfleghaar K, A ssel B, Johnson A, Rich RH. Predicting the uotcome of newborns with gastroschisis. J Pediatr Surg 2009;44:918-23.

66. David AL, Tan A, Curry J. Gastroschisis: Sonographic diagnosis, associations, management and outcome. Prenat Diagn 2008;28:633-44.

67. Weil BR, Leys CM, Rescorla FJ. The jury is still out: Changes in gastroschisis management over the last decade are associated with both benefits and shortcomings. J Pediatr Surg. 2012;47:119-24.

68. Juhasz-Boss I, Goelz R, Solomayer EF, Fuchs J, M eybergSolomayer G. Fetal and neonatal outcome in patients with anterior abdominal wall defects (gastroschisis and omphal ocele). J Perinat M ed 2011;40(1):85-90.

69. M ortellaro VE, St Peter SD, Fike FB, Islam S. Review of the evidence on the closure of abdominal wall defects. Pediatr Surg Int 2011;27:391-97.
70. $M$ artin $A E, K$ han $A, K$ im DS, M uratore CS, luks FI. The use of intra-abdominal tissue expanders as a primary strategy for closure of giant omphaloceles. J Pediatr Surg 2009;44:178-82.

71. Henrich $K$, Huemmer HP, Reingruber $B$, W eber PG. Gastroschisis and omphalocele: Treatments and long-term outcomes. Pediatr Surg Int 2008;24:167-73.

72. Deprest J, De Coppi P. A ntenatal management of isolated congenital diaphragmatic hernia today and tomorrow: Ongoing collaborative research and development. J Pediatr Surg 2012;47:282-90.

73. Sadler TW. L angman's M edical E mbryology. 9th Ed. Lippincott Williams \& W ilkins, Philadel phia, 2004.

74. Tovar JA. Congenital diaphragmatic hernia. Orphanet J Rare Dis 2012;7: http://www .ojrd.com/content/7/1/1

75. Deprest JA, Nicolaides K, Gratacos E. Fetal surgery for congenital diaphragmatic hernia is back from never gone. Fetal Diagn Ther 2011;29:6-17.

76. Lima M, Gargano T, Ruggeri G, M anuele R, Gentili A, Pilu G, Tani G, Salfi N. Clinical spectrum and management of congenital pulmonary cystic lesions. Pediatr M ed Chir 2008;30:79-88.

77. Chen HW, H su W M , L U FL, Chen PC, J eng SF, Peng SS, Chen $\mathrm{CY}$, Chou HC, Tsao PN, H sieh W S M anagement of congenital cystic adenomatoid malformation and bronchopulmonary sequestration in newborns. Pediatr Neonatol 2010;51:172-77.

78. Ikonomou T, Theodora M. Prenatal screening for congenital heart defects. D onal d School J ournal of U Itrasound in Obstetrics and Gynecology 2008;2:16-19.

79. Allan LD, Sharland GK, Chita SK, Lockhart S, M axwell DJ. Chromosomal anomalies in fetal heart congenital disease. Ultrasound Obstet Gynecol 1991;1:8-11.

80. Allan LD, Cook AC, Huggon IC. Fetal echocardiography. A practical guide. University Press, Cambridge, 2009.

81. Achiron R, W eissman A, Rotstein Z, Lipitz S, M ashiach S, Hegesh J. Transvaginal echocardiographic examination of the fetal heart between 13 and 15 w eeks of gestation in a low -risk population. J Ultrasound M ed 1994;13:783-89.

82. Chitayat $D, L$ anglois S, W ilson RD. Genetics Committee of the Society of Obstetricians and Gynaecologists of Canada; Prenatal Diagnosis Committee of the Canadian College of M edical Geneticists. Prenatal screening for fetal aneuploidy in singl eton pregnancies. J Obstet Gynaecol Can 2011;33:736-50.

83. Craigo SD. Indicated preterm birth for fetal anomalies. Semin Perinatol 2011;35:270-76.

84. Schaefer K G, Block SD. Physician communication with families in the ICU: Evidence-based strategies for improvement. Curr Opin Crit Care 2009;15:569-77.

85. Westgren M. Fetal medicine and treatment. Handbook Exp. Pharmacol 2011;205:271-83.

86. L awn JE, W ilczynska-K etende K, Cousens SN . Estimating the causes of 4 million neonatal deaths in the year 2000. Int J Epidemiol 2006;35:706-18.

87. Pinter $A B$. End-of-life decision before and after birth: Changing ethical considerations. J Pediatr Surg 2008;43:430-36.

88. Committee on F etus and N ew born. N oninitiation or withdrawal of intensive care for high-risk newborns. Pediatrics 2007; 119:401-03.

89. Provoost V, Cools F, Deconinck P, Ramet J, Deschepper R, Bilsen J, M ortier F, V andenplas $Y$, Deliens $L$. Consultation of 
parents in actual end-of-life decision-making in neonates and infants. Eur J Pediatr 2006;165:859-66.

90. Chiswick M. Infants of borderline viability: E thical and clinical considerations. Semin Fetal N eonatal M ed 2008;13:8-15.

91. Stanojevic M. Medical management of newborn with severe malformations- ethical aspects. In: Schenker GJ (Ed). Ethical dilemmas in perinatal medicine. J aypee Brothers $M$ edical Publishers, St. Louis, Panama City, D elhi, 2010:197-204.

\section{ABOUT THE AUTHORS}

\section{Sanja Zaputovic (Corresponding Author)}

Department of O bstetrics and Gynecology, M edical School U niversity of Zagreb, Clinical Hospital 'Sveti Duh', Sveti Duh 64, 10000 Zagreb Croatia, Phone: 00385-1-3712316, Fax: 00385-1-3745534 e-mail: sanjazaputovic@yahoo.com

\section{Milan Stanojevic}

Department of O bstetrics and G ynecology, M edical School U niversity of Zagreb, Clinical Hospital 'Sveti Duh', Zagreb, Croatia

\section{Ulrich Honemeyer}

Department of O bstetrics and Gynecology, W elcare Hospital, D ubai UAE

\section{Tanja Turudic}

Department of O bstetrics and Gynecology, M edical School U niversity of Zagreb, Clinical Hospital 'Sveti Duh', Zagreb, Croatia

\section{Asim Kurjak}

Department of O bstetrics and G ynecology, M edical School U niversity of Zagreb, Clinical Hospital 'Sveti Duh', Zagreb, Croatia 